\title{
DANOS AO DNA PROMOVIDOS POR ÁCIDO 5-AMINOLEVULÍNICO: POSSÍVEL ASSOCIAÇÃO COM O DESENVOLVIMENTO DE CARCINOMA HEPATOCELULAR EM PORTADORES DE PORFIRIA AGUDA INTERMITENTE
}

\author{
Janice Onuki*, Priscila C. Teixeira, Marisa H.G. Medeiros e Paolo Di Mascio \\ Departamento de Bioquímica, Instituto de Química, Universidade de São Paulo, CP 26077, 05513-970 São Paulo, SP
}

Recebido em 26/6/01; aceito em 1/10/01

\begin{abstract}
DNA DAMAGE INDUCED BY 5-AMINOLEVULINIC ACID: A POSSIBLE ASSOCIATION WITH THE DEVELOPMENT OF HEPATOCELLULAR CARCINOMA IN ACUTE INTERMITTENT PORPHYRIA PATIENTS. 5-Aminolevulinic acid (ALA) is a heme precursor accumulated in acute intermittent porphyria (AIP), which might be associated with hepatocellular carcinoma (HCC) in symptomatic patients. Under metal catalyzed oxidation, ALA and its cyclic dimerization product, 3,6-dihydropyrazine2,5-dipropanoic acid, produce reactive oxygen species that damage plasmid and calf thymus DNA bases, increase the steady state level of 8-oxo-7,8-dihydro-2'-deoxyguanosine in liver DNA and promote mitochondrial DNA damage. The final product of ALA, 4,5-dioxovaleric acid (DOVA), is able to alkylate guanine moieties, producing adducts. ALA and DOVA are mutagenic in bacteria. This review shows an up-to-date literature data that reinforce the hypothesis that the DNA damage induced by ALA may be associated with the development of HCC in AIP patients.
\end{abstract}

Keywords: 5-aminolevulinic acid; acute intermitent porphyria; DNA damage.

\section{PORFIRIAS}

As porfirias são definidas como doenças inatas ou adquiridas, relacionadas à deficiência de enzimas - inibição ou insuficiência - da via biossintética do grupo heme (Esquema 1) ${ }^{1}$. Esta deficiência resulta na produção excessiva e excreção de porfirinas e de seus precursores $^{2-6}$.

As porfirias são tradicionalmente classificadas com base no principal órgão que produz os metabólitos porfíricos em excesso (fígado ou os tecidos eritropoiéticos), na ocorrência ou não de ataques agudos e nas lesões cutâneas (fotossensibilidade) e/ou neurológicas produzidas ${ }^{5,7,8}$.

\begin{tabular}{lccc}
\hline Tipo de porfiria & Aguda & Hepática & Cutânea \\
\hline Porfiria deficiente em ALA desidratase & X & X & \\
Porfiria aguda intermitente (AIP) & X & X & \\
Coproporfiria hereditária (HCP) & X & X & X \\
Porfiria variegata (VP) & X & X & X \\
Porfiria cutânea tarda (PCT) & & X & X \\
Porfiria eritropoiética congênita (CEP) & & & X \\
Protoporfiria eritropoiética (EPP) & & & X \\
\hline
\end{tabular}

A natureza molecular do defeito genético é altamente heterogênea e defeitos múltiplos têm sido demonstrados em cada tipo de porfiria $^{3,5}$. Alguns modelos animais para os estudos dos diferentes tipos de porfiria já existem naturalmente, no caso de EPP e CEP e alguns foram desenvolvidos em laboratório, para EPP e porfirias hepáticas ${ }^{9,10}$, como a PCT ${ }^{11}$. Alguns estudos para aplicação de terapias gênicas em porfirias estão em andamento?

\section{O REI, O PINTOR, O ESCULTOR, O LOBISOMEM E O CONDE DRÁCULA}

O Rei George III da Inglaterra (1738-1820) começou em 1765 a apresentar ataques severos de dor abdominal, vômitos, taquicardia e urina vermelha escura e episódios de distúrbio mental. Esses sintomas são característicos de porfiria aguda e em 1966, Macalpine e Hunter sugeriram que provavelmente tratava-se de porfiria aguda intermitente (AIP). Há também relatos de que outros membros da família real britânica apresentavam sintomas semelhantes ${ }^{12}$. A doença do Rei George III é retratada no filme de Alan Bennett, "The Madness of King George".

O pintor pós-impressionista Vincent van Gogh (1853-1890), cuja insanidade fez-lhe cortar a própria orelha, apresentava períodos de extrema criatividade intermediados por episódios de uma doença debilitante, provavelmente AIP. Esta última condição era exacerbada por má nutrição, trabalho intenso e abuso de álcool, particularmente na forma de absinto ${ }^{13}$. Este licor, muito popular no século XIX na França, continha um grau elevado de álcool (74\%) e uma variedade de óleos essenciais, inclusive tujona, um terpeno tóxico responsável pela proibição do absinto ${ }^{14}$. Acredita-se que a inclinação de van Gogh por absinto resultou na tendência a beber terpenos, como tujonas, cânfora e pineno. Cânfora foi um medicamento popular na França do século XIX e van Gogh a tomava como um remédio caseiro para insônia ${ }^{14}$. Pineno é o principal constituinte do óleo de terebentina, usado para diluir pigmentos e lavar pincéis. Ocasionalmente, van Gogh tinha de ser controlado para não tomar terebentina ou "beliscar" suas tintas ${ }^{14}$.

$\mathrm{O}$ absinto contém uma série de terpenos e derivados, incluindo tujona $(2,4 \mathrm{mM})$ e álcool tujil $(0,8 \mathrm{mM})$. A concentração final na bebida, usualmente diluída seis vezes em água, era de cerca de 0,5 mM. Essa concentração pode ser suficiente, quando ingerida, para induzir ALA sintase (Esquema 1) hepática na presença de um bloqueio parcial da síntese do heme, precipitando sintomas de porfiria $^{15}$. Estudos demonstram que cânfora, pineno e tujona são porfirinogênicos em células de fígado de galinhas cultivadas e induzindo ALA sintase. Cânfora e tujona também induzem heme

\footnotetext{
*e-mail: janonuki@iq.usp.br
} 


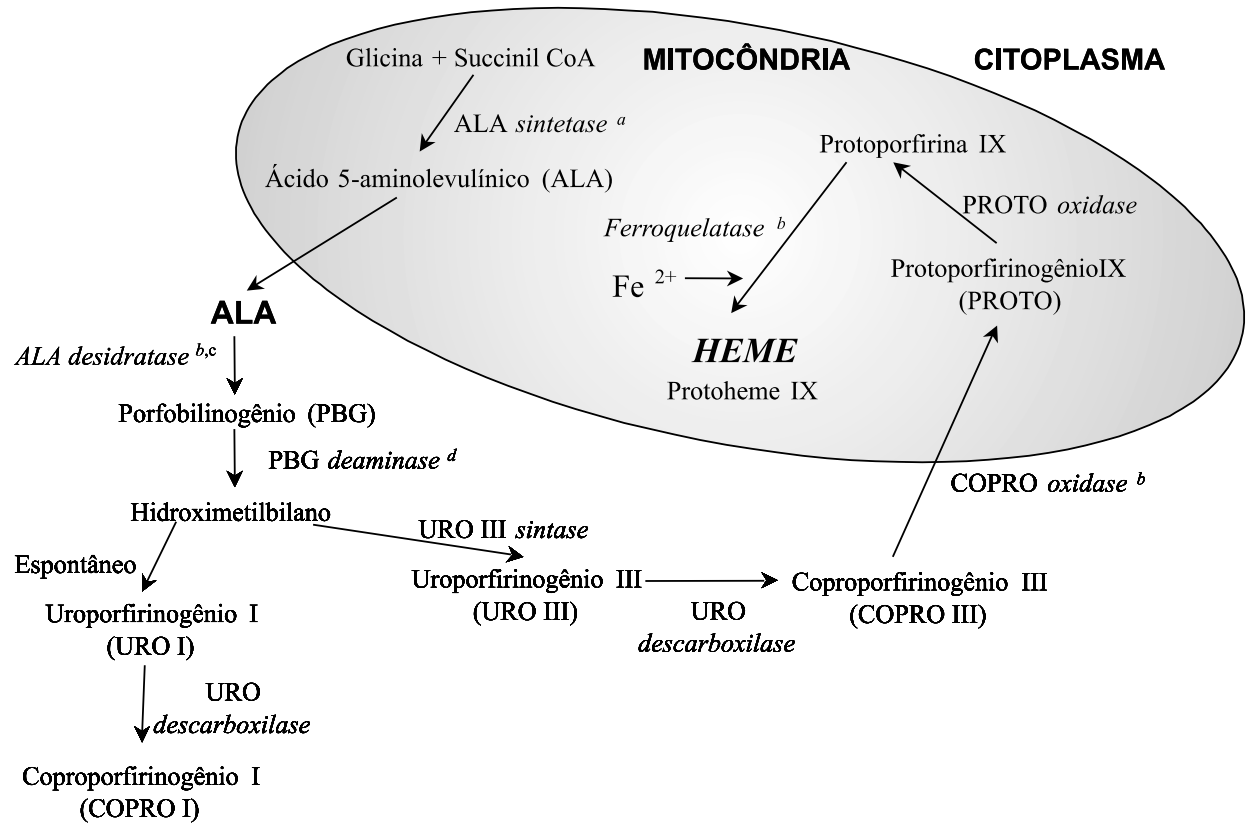

Esquema 1. Via biossintética do grupo heme, indicando as deficiências enzimáticas em porfirias com acúmulo de ácido 5-aminolevulínico (ALA) a - Retroinibição por heme, em AIP, ativada por drogas e metabólitos; b - Inibição por chumbo (Saturnismo); c - Inibição por succinilacetona (Tirosinemia); $\mathrm{d}$ - Biossíntese deficiente em Porfiria aguda intermitente

oxigenase por um mecanismo dependente de heme. Deste modo, pode ser inferido o potencial porfirinogênico do absinto (devido a tujona e constituintes terpenos), terebentina (pineno) e medicamentos contendo cânfora ${ }^{15}$.

O mais importante artista do Barroco brasileiro, o escultor mineiro Antônio Francisco Lisboa (1738-1814) conhecido como Aleijadinho, provavelmente também sofria de porfiria, talvez do tipo variegata, comum na tribo dos Banthus na África. Aleijadinho era filho de português com uma escrava africana. Há relatos que Aleijadinho possuia hábitos incomuns como trabalhar protegido por um toldo, sair para trabalhar de madrugada e retornar a noite e sempre usar roupas de mangas compridas. Sabe-se que as famosas esculturas dos 12 profetas de pedra sabão e as 66 estátuas de madeira das Capela dos Passos foram feitas entre 1796 e 1808, quando o artista já havia perdido parte dos dedos devido a sua doença. Para trabalhar ele pedia a alguém para amarrar o cinzel nas suas mãos.

Segundo artigos publicados no jornal Folha de S. Paulo de 16 de março de 1998, alguns acreditam que Aleijadinho era portador de hanseníase, entretanto seus ossos apresentavam pontos avermelhados. Para verificar se esses pontos poderiam ser resquícios de porfirinas, seus ossos foram exumados na Universidade Federal de Juiz de Fora. Entretanto, mesmo a origem de seus ossos é duvidosa pois quando faleceu, Aleijadinho foi enterrado em uma vala comum, somente sendo transferido em 1930 para uma urna especial. Infelizmente, o resultado da exumação dos ossos não foi publicado.

Uma das mais famosas lendas em todo mundo, a do lobisomem, provavelmente surgiu de indivíduos portadores de um tipo de porfiria, provavelmente a porfiria congênita eritropoiética ${ }^{1}$. Conhecida como doença de Günther, é uma doença rara autossômica recessiva, resultante da deficiência da uroporfirinogênio III sintase. Ocorre um acúmulo de uroporfirinogênio I e coproporfirinogênio I (Esquema 1) ocasionando fragilidade e fotossensibilidade da pele resultando em cicatrizes e deformações cutâneas. Outro sintoma é a fragilidade eritrocitária levando à anemia hemolítica. Podem também ocorrer hirsutismo, e descoloração de dentes, unhas e urina, tornando-os vermelhos devido ao acúmulo de porfirinas e deficiência no cresci- mento, tornando os portadores raquíticos. Além disso, a gengiva e os lábios podem se retrair expondo mais os dentes. Esses sintomas desfigurantes podem explicar parcialmente a lenda dos lobisomens surgida na Idade Média.

Provavelmente a mais conhecida e temida associação com a porfiria congênita eritrocitária é a figura do vampiro. Vários sintomas dessa doença podem estar associados aos comportamentos estranhos atribuídos ao famoso Conde Drácula e a outros menos notáveis portadores. No entanto, alguns autores alegam que tal associação não possui fundamentos e é imprecisa quanto aos sintomas atribuídos, uma vez que portadores de porfiria não desejam sangue, não são mortos pela exposição à luz do sol e não possuem poderes especiais ${ }^{1}$. Talvez esses mitos tenham surgido com base nos portadores de porfiria, mas acredita-se que grande parte seja resultado da imensa imaginação humana, capaz de exacerbar e atribuir falsos sintomas.

Em razão dessas associações entre figuras famosas ou lendárias e porfiria, comumente esse grupo de doenças recebe nomes populares como "doença do vampiro", "doença do lobisomem", "enfermidade real" ou "doença mental".

\section{PORFIRIAS QUE ACUMULAM ÁCIDO 5-AMINOLEVULÍNICO}

O interesse principal da nossa pesquisa são as porfirias que não ocasionam lesões cutâneas por fotossensibilidade e são caracterizadas pelo acúmulo e excreção urinária de ácido 5-aminolevulínico (ALA), o primeiro metabólito da biossíntese do heme (Esquema 1): intoxicação por chumbo, tirosinemia hereditária e porfiria aguda intermitente (AIP) $)^{3,5}$, que discutiremos com mais detalhes abaixo.

\section{INTOXICAÇÃO POR CHUMBO}

A intoxicação por chumbo, também chamada de saturnismo ou plumbismo caracteriza-se como uma porfiria adquirida. O chumbo afeta a biossíntese do heme, inibindo as enzimas ALA desidratase, coproporfirinogênio oxidase e ferroquelatase, levando ao acúmulo 
de ALA, coproporfirina e zinco protoporfirina (Esquema 12, ${ }^{2,16}$. As concentrações urinárias de ALA e de protoporfirina no sangue são consideradas indicadores biológicos da intoxicação por chumbo. $\mathrm{O}$ estabelecimento de níveis mínimos de chumbo no sangue para que ocorra um aumento da excreção urinária de ALA pode ser importante para análises de dados experimentais epidemiológicos como relatados por Higashikawa et al. ${ }^{17}$.

Costa et al. ${ }^{18}$ mostraram que trabalhadores expostos ao chumbo apresentaram um nível 6 vezes maior de concentração de ALA plasmático e concomitante aumento dos níveis de protoporfirina IX, atividade da superóxido dismutase (SOD), metahemoglobina e de quimioluminescência urinária ${ }^{18}$. Esse quadro é consistente com a hipótese de que o ALA poderia estar promovendo estresse oxidativo ${ }^{4}$.

Os sintomas característicos são anemia, insuficiência renal, fraqueza neuromuscular, ataques de apoplexia e coma ${ }^{19}$, além de efeitos genéticos ${ }^{20}$. Hermes-Lima et al. ${ }^{21}$ postularam que as espécies reativas de oxigênio (ROS) produzidas pela oxidação do ALA poderiam estar envolvidas na patogênese da intoxicação por chumbo (vide item: $O$ ALA e seu potencial oxidante). Vários estudos relatam a utilização de antioxidantes no tratamento dos sintomas da intoxicação por chumbo, como revisado por Gurer e $\mathrm{Ercal}^{22}$.

Além disso, a intoxicação por chumbo é considerada uma doença ocupacional séria ${ }^{23}$ e pode ser uma fonte potencial, em áreas urbanas, de danos cerebrais, retardamento mental e problemas comportamentais graves em bebês ${ }^{16,24}$. Na Europa, por exemplo, o encanamento de água nas casas que era feito de chumbo, foi trocado.

\section{TIROSINEMIA HEREDITÁRIA}

A tirosinemia hereditária, também conhecida como tirosinemia hepatorenal, tirosinemia do tipo I ou tirosinose congênita, é causada por uma deficiência da fumarilacetoacetato hidrolase (FAH), a enzima envolvida no último passo do catabolismo da tirosina. Essa deficiência resulta na produção aumentada de succinilacetona que compete fortemente com o ALA na reação da ALA desidratase e deste modo, resulta num acúmulo de ALA. As mutações no gene da FAH que levam à tirosinemia são heterogêneas ${ }^{25}$.

Os sintomas são muito variáveis e incluem falha hepática aguda, carcinoma hepatocelular, síndrome de Fanconi renal, cirrose, glomeruloesclerose e crises de neuropatia periférica.

O diagnóstico da doença é feito pela presença de succinilacetona na urina ou no sangue. Muitos pacientes respondem à restrição de fenilalanina e tirosina na dieta. $\mathrm{O}$ transplante de fígado cura as manifestações hepáticas e previne as crises neurológicas. $\mathrm{O}$ tratamento com 2-(2-nitro-4-trifluorometilbenzoil)1,3-cicloexanodiona, (NTBC), um inibidor da 4-hidroxifenilpiruvato dioxigenase (que participa do catabolismo da tirosina), normaliza as funções renais e hepáticas. Já foi reportada a correção da deficiência da FAH em fibroblastos humanos em cultura por transferência gênica mediada por retrovírus ${ }^{26}$.

\section{PORFIRIA AGUDA INTERMITENTE}

A porfiria aguda intermitente também denominada porfiria sueca, pirroloporfiria e porfiria intermitente aguda ${ }^{5,27}$ é uma desordem hereditária autossômica dominante, relativamente rara, mas que é encontrada em diversas populações ${ }^{8}$. Nos Estados Unidos, a incidência do defeito gênico afeta entre 5-10 em cada 100 mil indivíduos e na Austrália 3 em 100 mil $^{28}$. Na Suécia, país de maior prevalência da doença, estimam-se 10 casos em cada 100 mil habitantes ${ }^{6}$.

O defeito primário da AIP está no gene que codifica para a terceira enzima da síntese do heme, a PBG deaminase (PBGD), que catalisa a síntese do hidroximetilbilano a partir do porfobilinogênio
(Esquema 1). Mutações nesse gene resultam em mudanças na sequiência de aminoácidos da proteína e deleções em certas regiões que levam à diminuição da atividade da enzima.

Há vários métodos de diagnóstico de AIP: a verificação da diminuição da atividade da PBGD nos eritrócitos, encontrada em cerca de $80 \%$ dos portadores de AIP $^{29,30}$, a análise dos níveis de ALA e PBG na urina, que quase sempre aumentam durante os ataques de $\mathrm{AIP}^{5,31}$, e também a análise genética ${ }^{32}$. Dessa forma têm sido utilizados diversos métodos, em conjunto com a identificação dos sintomas clínicos e análise do histórico familiar, para identificação mais precisa da AIP.

Apesar de haver vários métodos de diagnóstico, ainda há dificuldade de identificação ${ }^{33}$ decorrente do fato da doença permanecer latente em muitos casos. Somente $20-50 \%$ dos portadores do gene apresentam os sintomas clínicos, sendo que esses sintomas são muito variáveis e comuns a outras doenças ${ }^{34,35}$. Geralmente os sintomas, caracteristicamente intermitentes, aparecem após a puberdade e são mais comuns em mulheres do que em homens. Há alta incidência de ataques severos de dores abdominais seguidos de dores nas costas e nos membros, vômitos, constipação, taquicardia e fraqueza muscular. Hipertensão é reportada em 40-60\% dos $\operatorname{casos}^{36}$. Os sintomas neurológicos característicos são ataques epilépticos e encefalopatia ${ }^{37}$ e manifestações psiquiátricas como ansiedade, insônia, depressão e irritabilidade. Em ataques severos, podem ocorrer paranóia, confusão e alucinações ${ }^{36}$.

A maioria dos ataques é precipitada por fatores endógenos ou exógenos ambientais, porém a causa dos ataques permanece desconhecida em cerca de $30 \%$ dos $\operatorname{casos}^{38}$.

Há diversos fatores que podem levar a AIP latente a se manifestar, como certas drogas (sulfonamidas e barbituratos) ${ }^{5}$, hormônios sexuais endógenos ${ }^{39}$ ou exógenos ${ }^{40}$, excesso de álcool ${ }^{41}$, nutrição inadequada $^{42}$, estresse ${ }^{43}$, infecções ${ }^{44}$, fumo ${ }^{45}$ e certas substâncias químicas, como terpenos, solventes orgânicos, drogas lipofílicas ${ }^{15}$. Entretanto a sensibilidade a esses fatores é muito variável entre os pacientes e até mesmo em um mesmo indivíduo ${ }^{41}$. Sabe-se que as mulheres são mais afetadas pela doença havendo uma correlação entre os sintomas clínicos e o ciclo menstrual ${ }^{46}$.

O mecanismo exato que leva esses fatores a precipitarem os ataques que constituem os sintomas clínicos da doença ainda não é consensual. Algumas drogas induzem citocromo P450 e aumentam a demanda metabólica por heme no fígado, podendo levar a uma indução da atividade da ALA sintase ${ }^{47}$. Porém, algumas drogas, como as sulfonamidas, parecem inibir diretamente a PBG deaminase, sob um mecanismo independente da indução de citocromo $\mathrm{P} 450^{48}$.

O tratamento da AIP é baseado na profilaxia, em terapias específicas para diminuir os níveis de precursores do heme e no tratamento dos sintomas da doença. Vários tipos de terapia têm sido propostos para atenuar as sintomas da $\mathrm{AIP}^{49}$, como a ingestão de grande quantidade de carboidratos ${ }^{50}$, a infusão intravenosa de hematina ${ }^{51}$, o uso de heme $\operatorname{arginato}^{52}$, de metaloporfirinas sintéticas ${ }^{53}$, zinco mesoporfirina $^{54}$, e outras drogas em estudo como propanolol, a 3,5,3'triiodotreonina, esteróides, agentes quelantes ${ }^{5}$, cimetidina ${ }^{55}$ e agentes antioxidantes ${ }^{56}$.

Algumas doenças têm sido associadas à AIP. A hipertensão e a falha renal têm sido encontradas em muitos pacientes que sofrem de $\mathrm{AIP}^{57}$. A hipertensão tem sido associada à AIP durante os ataques agudos, mas pouco se conhece da sua prevalência como uma doença crônica. A hipertensão pode contribuir para a patogênese da falha renal crônica, reportada em pacientes portadores de AIP $^{58}$.

Outra doença que possivelmente pode estar associada à AIP é o lupus eritematoso sistêmico, onde ocorre a formação de anticorpos antinucleares $^{59}$. Porém, essa associação não é muito evidente, podendo ser somente uma coincidência rara ${ }^{34}$. 
Alguns modelos animais já foram descritos para estudos da porfiria aguda intermitente, como o tratamento de ratos com injeção intraperitoneal de $\mathrm{ALA}^{60}$ e o tratamento com succinilacetona metil ester que inibe e a ALA desidratase (Esquema 1) ${ }^{61}$. Também já foi desenvolvido um modelo de rato por recombinação homóloga ${ }^{10}$ para estudos de porfirias agudas.

\section{PORFIRIA AGUDA INTERMITENTE E CARCINOMA HEPATOCELULAR}

A associação entre a AIP e o carcinoma hepatocelular (HCC) foi primeiramente descrita por Lithner e Wetterberg ${ }^{62}$. Entre os 206 portadores do gene da PBGD alterado, foram encontrados 11 casos de HCC (5\%). Hardell et al.$^{63}$ relataram três casos de AIP entre 83 pacientes com HCC (4\%). Outro estudo revelou 5 casos de HCC em duas famílias com 15 portadores de $\mathrm{AIP}^{64}$. Em estudos de Kauppinen e Mustajoki ${ }^{65}, \mathrm{HCC}$ foi a causa de morte de 6 dos 64 pacientes com AIP (9\%) e em 1 dos 18 pacientes com porfiria variegata. Esses autores detectaram que pacientes com AIP apresentavam um risco 61 vezes maior de desenvolvimento de HCC. Gubler et al. ${ }^{66}$ relataram o caso de duas irmãs portadoras de AIP que desenvolveram HCC. Thunnissen et al. ${ }^{67}$ reportaram um caso de um paciente homem de 67 anos que desenvolveu HCC sem exposição a fatores de risco ambiental, metabólico ou viral; a única causa encontrada foi a AIP. Andersson $e t$ al. ${ }^{6}$ relataram também que $\mathrm{HCC}$ foi a causa da morte de $27 \%$ dos pacientes com AIP, sendo mais comum em mulheres e em pacientes sintomáticos. Em um estudo com 650 pacientes de AIP acompanhados durante 7 anos, foram encontrados 7 casos de HCC, sendo 4 mulheres e 3 homens ${ }^{68}$.

\section{PATOGÊNESE DOS SINTOMAS}

Várias são as hipóteses levantadas para explicar a patogênese dos sintomas associados à AIP: depleção de substrato de cofatores provenientes da biossíntese deficiente de heme; neurotoxicidade resultante do excesso de precursores de porfirinas e deficiência intracelular de heme $5,38,43,69$.

Ratos deficientes em porfobilinogênio deaminase ${ }^{10}$ que apresentam características bioquímicas de AIP, como o aumento da excreção urinária de ALA, desenvolvem neuropatias periféricas muito semelhantes às porfirias agudas humanas sugerindo que a deficiência de heme e a conseqüente disfunção de hemeproteínas poderiam ser as causas dessas neuropatias ${ }^{70}$. Jover et al. ${ }^{71}$ relataram uma diminuição da atividade e dos níveis de RNA mensageiro do citocromo P450 nesses ratos deficientes em PBGD, induzida por fenobarbital ${ }^{71}$.

Os efeitos tóxicos dos precursores de porfirinas produzidos em excesso, como ALA e PBG, também poderiam explicar a patogênese dos sintomas. Todos distúrbios metabólicos, caracterizados pelo acúmulo de ALA, são acompanhados por distúrbios neurológicos similares, como as quatro porfirias agudas, a tirosinemia hereditária e a intoxicação por chumbo ${ }^{5}$.

A barreira hematoencefálica é pouco permeável ao ALA e ao PBG, mas durante os ataques agudos de AIP essas substâncias podem ser detectadas no fluido cerebroespinhal, onde não são detectados em condições normais ${ }^{69,72,73}$.

A concentração no tecido nervoso pode ser ainda maior quando comparada aos níveis mais baixos no fluido cerebroespinhal, uma vez que experimentos demonstraram que os neurônios podem concentrar ativamente o ALA. Os ataques agudos somente ocorrem quando há uma elevação das concentrações de ALA e de PBG. No entanto, há pacientes que apresentam concentrações elevadas mesmo nos períodos sem sintomas. Nestes casos, as exacerbações são acompanhadas de uma maior excreção desses compostos ${ }^{69}$.
Além disso, têm-se demonstrado que o ALA, gerado no fígado e na medula óssea, é capaz de atravessar a barreira hematoencefálica e se distribuir por outros órgãos ${ }^{60,74}$. A administração aguda de altas doses de ALA em animais promoveu efeitos excitatórios transientes e mudanças comportamentais ${ }^{60}$. Em um estudo realizado em humanos, a infusão de ALA por 92 horas elevou o nível plasmático de ALA até o encontrado nos ataques agudos. No entanto, nenhum sintoma foi relatado ${ }^{75}$. ALA também foi capaz de inibir a adenilato ciclase em cérebros de ratos e humanos ${ }^{76}$.

Uma combinação entre estresse oxidativo, excesso de ALA e deficiência de heme também poderia explicar os sintomas clínicos da $\mathrm{AIP}^{43}$. AIP pode ser considerada como uma doença que leva a um estado constante de estresse oxidativo com uma sobrecarga de radicais livres periódica. Isso pode acarretar alterações neurológicas agudas e, a longo prazo, lesões hepáticas e renais. De fato, o ALA tem sido relatado como sendo o agente principal no processo metabólico que leva às manifestações neurológicas da doença ${ }^{77}$.

Foi demonstrado, in vitro, que o ALA é capaz de gerar ROS durante sua oxidação catalisada por íons ferro ${ }^{78,79}$ (vide item: $A L A e$ seu potencial oxidante). O ALA pode gerar ROS in situ que levariam à lesão de neurônios e células da glia ${ }^{80}$. A vulnerabilidade poderia ser dependente do balanço entre os fatores geradores de ROS (fatores que precipitam os ataques) e da defesa antioxidante.

Componentes chave nesse processo seriam as enzimas antioxidantes, o "pool" de heme e o citocromo P450. Esse modelo sugere que alguns fatores precipitantes dos ataques poderiam agir exacerbando os efeitos deletérios das ROS. O uso terapêutico de heme em AIP pode ser explicado também pelo fato do heme ser um dos mais efetivos quelantes de ferro o que reduziria a ação das $\operatorname{ROS}^{43}$.

\section{PATOGÊNESE DO CARCINOMA HEPATOCELULAR EM PORFIRIA AGUDA INTERMITENTE}

A causa da maior prevalência de HCC nos pacientes com AIP ainda não está estabelecida.

Bengtsson et al. ${ }^{64}$ sugeriram que o gene da PBGD poderia funcionar como um gene supressor de tumor. No entanto, Bjersing et $a l .{ }^{81}$ não encontraram nenhum alelo mutado ou perdido no gene da PBGD, nem mesmo nos tecidos tumorais. Outra possibilidade remota seria que a proteína truncada codificada pelo gene da PBGD mutado poderia alterar a transcrição do gene, como por exemplo ligando-se a proteína p53. Isso imitaria funcionalmente uma mutação em p53 e seria consistente com as poucas mutações em p53 encontradas por Bjersing et al. ${ }^{81}$.

Outra alteração em pacientes com AIP durante os ataques é o aumento de níveis séricos de aminotransferases, indicando danos às células hepáticas que poderiam estar relacionados à morfologia de pré-cirrose e cirrose encontrados em vários casos estudados por Andersson et al. ${ }^{6}$. A cirrose geralmente aumenta o risco de desenvolvimento de HCC; a destruição de células parenquimáticas e a fibrinogênese, no processo cirrótico, estimulam a regeneração celular e aumentam o risco de câncer ${ }^{6}$.

Outra hipótese sugere que o mecanismo de detoxificação do organismo fica alterado na AIP, levando ao acúmulo de substâncias carcinogênicas ${ }^{62}$.

Bengtsson et al. ${ }^{64}$ sugeriram que as porfirinas seriam carcinogênicas per se, uma vez que a principal consequiência da mutação no gene da PBGD deaminase é o acúmulo de ALA e PBG. O carcinoma hepatocelular foi encontrado somente em grupos de pacientes com AIP que apresentavam excreções urinárias de ALA e PBG elevadas $^{62}$. Pacientes sintomáticos de AIP possuem um nível de excreção urinária de PBG cinco vezes maior, e de ALA, três vezes maior, quando comparados a pacientes com AIP latente ${ }^{43}$. Além disso, HCC 
é mais comum em pacientes sintomáticos de AIP do que em latentes $^{6}$. Essas evidências suportam a hipótese de que os precursores poderiam ser carcinogênicos.

Outra hipótese a ser considerada no que se refere à maior incidência de HCC em AIP, seria a combinação entre a redução da quantidade de heme livre, resultando em níveis mais baixos de P-450 e outras heme enzimas importantes na defesa antioxidante, e o aumento do estresse oxidativo proveniente do acúmulo do ALA (vide item: $O$ ALA e seu potencial oxidante). As espécies reativas de oxigênio produzidas poderiam atacar aleatoriamente o genoma das células hepáticas e, eventualmente, algum gene relacionado ao estabelecimento do processo carcinogênico.

Bjersing et al.$^{81}$ investigaram mutações nos códons 249 e 166 no gene p53 em pacientes com HCC e AIP em áreas com baixa exposição à aflotoxina B1 e ao vírus da hepatite B. Nenhuma mutação foi encontrada no códon 249 e a mutação no códon 166 somente foi verificada em um tumor. Nenhuma mutação foi encontrada em Hras 12 ou $61^{81}$.

\section{O ÁCIDO 5-AMINOLEVULÍNICO E SEU POTENCIAL PRÓ-OXIDANTE}

O ALA, o primeiro precursor do grupo heme acumulado em pacientes sintomáticos de AIP, sofre enolização sob $\mathrm{pH}$ básico e conseqüente oxidação catalisada por complexos de ferro gerando ROS e o aldeído ácido 4,5-dioxovalérico (DOVA) como produto final $^{78,82}$ (Figura 1). Monteiro et al. ${ }^{82}$ demonstraram que o ALA é capaz de acelerar a conversão da oxihemoglobina a metahemoglobina, sendo oxidado neste processo. A intermediação de ROS na reação foi evidenciada pelo efeito inibitório da superóxido dismutase e da catalase $^{82}$.

O mecanismo de oxidação do ALA, a formação do radical ${ }^{\circ} \mathrm{OH}$ e de um radical centrado no carbono foram inferidos a partir de análises cinéticas e de ressonância paramagnética eletrônica $(\mathrm{EPR})^{78}$. Estudos utilizando folhas de alface e trigo como modelo para verificação do mecanismo da ação herbicida do ALA sob irradiação ${ }^{83}$, detectaram adutos de radicais livres por EPR de espectro idêntico àquele atribuído por Monteiro et al. ${ }^{78}$. Vários estudos revelaram o potencial oxidante do ALA sobre diferentes sistemas celulares ${ }^{4,84}$.

Estudos realizados com mitocôndrias de fígado de rato sustentadas com succinato na presença de ALA, revelaram alterações nas propriedades mitocondriais como o colapso do potencial da membrana, inchamento e liberação da taxa respiratória na presença de íons cálcio. Catalase, SOD e $o$-fenantrolina inibiram tais processos, indicando a participação de $\mathrm{H}_{2} \mathrm{O}_{2}$ e íons ferro ${ }^{79,85}$. A remoção do $\mathrm{Ca}^{2+}$ pela adição de EGTA aboliu tanto o colapso do potencial da membrana quanto o inchamento da mitocôndria ${ }^{85}$.

Vercesi et al..$^{86}$ propuseram que a permeabilização da membrana mitocondrial induzida por $\mathrm{Ca}^{2+}$ na presença de ALA seria mediada pelo ataque de ROS a grupamentos tiólicos de proteínas da membrana mitocondrial, formando agregados proteicos de alto peso molecular, resultando na formação de poros não específicos. A ligação do $\mathrm{Ca}^{2+}$ aos agregados proteicos desempenharia um papel importante na abertura dos poros.

Hermes-Lima sugeriu um modelo de duas etapas para explicar a participação do $\mathrm{Ca}^{2+} \mathrm{e}$ das ROS na indução dos danos à mitocôndria promovidos por ALA. As ROS, derivadas da oxidação do ALA, promoveriam a transição da membrana interna da mitocôndria de um estado nativo (impermeável I) para um estado suscetível (impermeável II), através da oxidação de grupos tiólicos de proteínas. A ação do $\mathrm{Ca}^{2+}$ seria promover mudanças conformacionais nessas proteínas, levando à passagem para um estado permeável através da abertura de um poro na membrana interna da mitocôndria ${ }^{87}$.

Pereira et al..$^{88}$ mostraram que o ALA também exerce um papel pró-oxidativo in vivo: ratos tratados com ALA cronicamente sofreram alterações metabólicas, enzimáticas e fisiológicas, indicando o aumento do metabolismo glicolítico associado ao dano mitocondrial do fígado e do músculo esquelético estriado. Esses dados são consistentes com os achados prévios de Biempica et al. ${ }^{89}$; analisando amostras de biópsia de fígado de quatro pacientes com AIP, estes autores encontraram numerosas gotas de lipídios, abundantes grânulos de ferritina, largos corpos de lipofuscina, mitocôndrias com formas alteradas e hiperplasia do retículo endoplasmático liso e de vacúolos autofágicos contendo mitocôndrias bem preservadas. Es-<smiles>NCCC(=O)CCC(=O)OC(=O)CCC(=O)CN</smiles><smiles>[Mg]</smiles><smiles>NC=C(CCC(=O)O)CCC(=O)CCC(=O)[O-]</smiles>

ALA (enol)<smiles>N/C=C(/O)CCC(=O)[O-]</smiles>

ALA (enol)<smiles>N=CC(=O)CCC(=O)O</smiles><smiles>CC(O)CN</smiles>

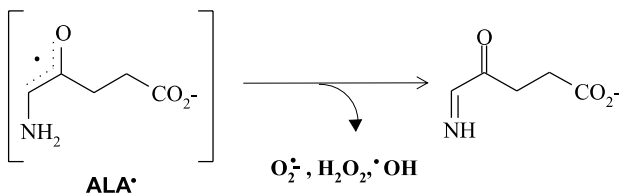

ALA<smiles>O=CC(=O)CCC(=O)[O-]</smiles> 
sas alterações podem ser atribuídas ao extenso dano oxidativo iniciado pelo ALA.

In vitro, ALA prejudica as funções mitocondriais de fígado de rato e in vivo, promove a perda das atividades da citrato sintase e da SOD dependente de magnésio ${ }^{88}$.

Oteiza e Bechara ${ }^{90}$ demonstraram que o ALA é capaz de induzir peroxidação lipídica em lipossomos ricos em cardiolipinas e que tal processo é inibido pela adição de $\alpha$-tocoferol. Alterações na fluidez da membrana e peroxidação lipídica de microssomos e membranas mitocondriais induzidas por ALA também foram inibidas por melatonina ${ }^{91,92}$.

O efeito pró-oxidante do ALA também foi demonstrado em tecido cerebral de ratos. Após duas semanas de tratamento com ALA ( $40 \mathrm{mg} / \mathrm{kg}$ peso corporal) vários parâmetros indicadores de estresse oxidativo apresentaram níveis aumentados: atividade de CuZnSOD, quantidade de ferro total, ferritina, carbonilas proteicas e captação de $\mathrm{Ca}^{2+}$ por sinaptossomas corticais. Além disso, membranas sinápticas apresentaram alterações de afinidade de ligação nos receptores de GABA, formação de grupos carbonílicos protéicos, produtos reativos ao ácido tiobarbitúrico (TBARS) e dienos conjuga$\operatorname{dos}^{77}$. A inibição de adenilato ciclase por ALA em membranas isoladas de cérebro de ratos e de humanos também foi relatada; a adição de antioxidantes como ascorbato, glutationa ou Trolox ${ }^{\circledR}$ preveniu completamente tal inibição, indicando a participação de $\operatorname{ROS}^{76}$.

Células de ovário de hamster chinês $(\mathrm{CHO})$ apresentaram inibição da formação de colônias e de sobrevivência celular quando tratados com ALA. Foram observados também diminuição do nível de glutationa reduzida (GSH) e aumento dos níveis de glutationa oxidada (GSSG) e malonaldeído (MDA). A adição de $N$-acetilcisteína foi capaz de minimizar os efeitos sobre a sobrevivência celular e os níveis de GSH e $\mathrm{GSSG}^{93}$. O ferro também desempenha papel importante nas lesões promovidas pelas ROS uma vez que está envolvido na formação destas, participa da oxidação do $\mathrm{ALA}^{4}$ e também está presente no núcleo celular associado ao $\mathrm{DNA}^{94}$. O ALA foi capaz de induzir a ativação da proteína regulatória de ferro citossólico 1 (IRP1) ${ }^{95}$ que controla a homeostase do ferro celular ${ }^{96-98}$ e que é reconhecidamente ativada por alguns oxidantes ${ }^{99-102}$. Deste modo, a ferritina, principal proteína armazenadora de ferro no organismo, também pode estar envolvida nas lesões. Já foi demonstrado que o ALA é capaz de liberar ferro da ferritina através do ânion superóxido gerado a partir de sua oxidação ${ }^{103,104}$. A liberação potencialmente deletéria de ferro de microssomas induzida por ALA foi também observada por Minotti ${ }^{105}$.

Rocha et al. ${ }^{61}$ relataram que ratos tratados com succinilacetona metil éster apresentaram aumento do nível plasmático de ALA, do nível de ferro livre no fígado e no cérebro. A mobilização de ferro também foi indicada pelo aumento de ferro plasmático e da saturação da transferrina no plasma. Aumento no nível de ferritina no fígado também foi relatado. Foram evidentes também indicações do estresse oxidativo como o aumento dos níveis de carbonilas proteicas reativas no fígado, aumento de TBARS e da atividade de CuZnSOD no cérebro. Esses dados corroboram com a hipótese de que o acúmulo do ALA na tirosinemia e nas porfirias agudas poderia promover danos biológicos dependentes de ferro que contribuiria para as neuropatias e para os hepatomas relatados nos pacientes de AIP.

\section{DANOS AO DNA PROMOVIDOS POR ÁCIDO 5-AMINOLEVULÍNICO E SEUS DERIVADOS}

\section{Danos ao DNA promovidos por espécies reativas de oxigênio}

Nossos estudos demonstraram que o ALA é capaz de promover quebras de fita simples no DNA plasmidial mediadas por íons $\mathrm{Fe}^{2+}$. A redução ou até a supressão das quebras de fita simples por SOD, catalase e ácido dietilenetriaminopentaacético (DTPA) indicaram claramente o envolvimento de uma série de reações bem conhecidas (reações 1-5) ${ }^{106}$.

$$
\begin{aligned}
& \mathrm{ALA}+\mathrm{O}_{2} \longrightarrow \stackrel{\text { Ferro }}{\longrightarrow} \longrightarrow \mathrm{DOVA}+\mathrm{NH}_{4}^{+}+\left(\mathrm{O}_{2}{ }^{-}, \mathrm{H}_{2} \mathrm{O}_{2}\right) \text { (reação 1) } \\
& \mathrm{O}_{2}^{-\cdot}+\mathrm{O}_{2}^{\cdot-}+2 \mathrm{H}^{+} \longrightarrow \mathrm{H}_{2} \mathrm{O}_{2}+\mathrm{O}_{2} \\
& \mathrm{Fe}^{3+}(\text { ferritina })+\mathrm{O}_{2}^{--} \longrightarrow \mathrm{Fe}^{2+}(\text { ferritina })+\mathrm{O}_{2} \\
& \mathrm{Fe}^{2+}+\mathrm{H}_{2} \mathrm{O}_{2} \longrightarrow \mathrm{Fe}^{3+}+\mathrm{OH}+\mathrm{OH} \\
& \cdot \mathrm{OH}+\mathrm{DNA} \longrightarrow \longrightarrow \text { lesões ao DNA }
\end{aligned}
$$

A ferritina também poderia participar das reações envolvidas nas lesões ao DNA promovidas por ALA. O aumento do número de quebras no DNA plasmidial e da 8-oxo-7,8-dihidroxi-2'-desoxiguanosina (8-oxodGuo) em DNA de timo de bezerro incubados com ALA na presença de ferritina são indícios de que esta pode aumentar os efeitos do ALA através da liberação do $\mathrm{Fe}^{2+}$, tornando-o disponível para participar da reação de oxidação ${ }^{107}$.

Outros resultados obtidos corroboram com a hipótese de que o ALA poderia promover danos oxidativos ao DNA. Foram detectados níveis aumentados, in vitro e in vivo, de 8-oxodGuo em DNA de timo de bezerro e em DNA de órgãos de ratos tratados cronicamente com $\mathrm{ALA}^{108}$. Dados descritos por Yusof et al. ${ }^{109}$, demonstraram que o ALA é capaz de induzir a produção de 8-oxodGuo em células de ovário de hamster chinês, indicando a participação das ROS através da diminuição dos danos pela adição de SOD, catalase e $N$ acetilcisteína. O aumento de 8-oxodGuo em DNA de timo de bezerro e em pulmão e baço de ratos tratados com ALA foram inibidos pela adição de melatonina, manitol e trolox ${ }^{91,110}$.

Vários estudos utilizam a formação de 8-oxodGuo como um índice de lesões oxidativas ao DNA por diversos agentes químicos e físicos que produzem ROS, como agentes redutores ${ }^{111}$, raios $\mathrm{X}^{112}$, asbestos e $\mathrm{H}_{2} \mathrm{O}_{2}{ }^{113,114}$, polifenol com $\mathrm{H}_{2} \mathrm{O}_{2}$ e íon férrico ${ }^{113}$, radiação ionizante ${ }^{115}, \mathrm{H}_{2} \mathrm{O}_{2}$ na presença de luz $\mathrm{UV}^{116}$, azul de metileno na presença de luz ${ }^{117}$, oxigênio singlete $\left({ }^{1} \mathrm{O}_{2}\right)^{118}$, radiação gama ${ }^{119,120}$ e diversos agentes mutagênicos, promotores de tumor ${ }^{121}$ e carcinogênicos ${ }^{122}$.

A medida de 8-oxodGuo em rins e fígado foi utilizada em estudos de exposição a metais como o cobre, encontrando-se um aumento significativo na formação da base modificada ${ }^{123,124}$. Além disso, a formação de 8-oxodGuo também foi utilizada como um índice para avaliar o dano oxidativo ao DNA de diferentes órgãos de ratos em relação à idade ${ }^{125}$ e verificar a influência do fumo e da massa corporal em homens e mulheres ${ }^{126}$.

A relação entre a geração de ROS in vivo e a carcinogênese tem sido muito estudada ${ }^{127}$ e a formação de bases oxidadas como a 8oxodGuo pode estar intimamente envolvida no início de um processo carcinogênico ${ }^{128}$. Várias são as evidências que reforçam a participação da 8-oxodGuo como lesão pré-mutagênica na carcinogênese ${ }^{129}$.

A presença de 8-oxodGuo no DNA molde causa uma incorporação errônea de nucleotídeos no DNA replicado pela $\alpha$-polimerase. Quando a 8-oxodGuo está antes de uma purina, a incorporação errônea é mais acentuada. Parece haver menor seletividade no nucleotídeo inserido opostamente a 8 -oxodGuo ${ }^{130}$. Wood et al. ${ }^{131}$ indicaram que a inserção de uma pequena sequiência de DNA contendo 8-oxodGuo no lugar de dGuo no codon âmbar do gene do fago LacZ, aumentou o número de mutantes, com a ocorrência de transversão $\mathrm{G} \rightarrow \mathrm{T}$ no sítio de lesão. Resultados similares foram obtidos em estudo de replicação de plasmídios utilizando uma lesão de fita única ${ }^{132}$ e um fago vetor dupla fita ${ }^{133}$. Em células de mamíferos com a 8-oxodGuo 
posicionada em um único sítio em DNA epissomal foi observada transversão $\mathrm{G} \rightarrow \mathrm{T}^{134,135}$. Em ensaios in vitro de incorporação de nucleotídeos frente à 8-oxodGuo, utilizando diferentes polimerases, foi observado que as enzimas envolvidas na replicação do DNA (polimerase $\alpha$, polimerase $\delta$ e polimerase III) tendem a inserir adenina frente a 8-oxodGuo, já as polimerases envolvidas em síntese de reparo (polimerase $\beta$ e polimerase I e polimerase $\gamma$ ) tendem a inserir citosina frente à lesão ${ }^{136}$.

Para que uma lesão ao DNA possa resultar em mutações ela deve persistir durante os ciclos de replicação celular. Entretanto, para manter a integridade do material genético, a célula possui uma eficiente maquinaria de reparo do DNA. Kasai et al. ${ }^{15}$ verificaram a presença de 8-oxodGuo após irradiação das células HeLa e de fígado de camundongos com raios X e $\gamma$. Analisando o DNA, em diferentes tempos após a irradiação, observou-se a redução progressiva da quantidade de 8-oxodGuo, sugerindo o reparo do DNA.

Além da medida de 8-oxodGuo em DNA de fígado de ratos tratados com ALA, também foram obtidas medidas em baço e rins. $\mathrm{O}$ aumento de 8-oxodGuo em rins poderia estar relacionado à falha renal crônica reportada em portadores de $\operatorname{AIP}^{57}$ e aos distúrbios renais encontrados na tirosinemia hereditária ${ }^{25}$.

In vivo, também reportamos um aumento de 5-hidroxi-2'desoxicitidina (5-OHCyd) em DNA de fígado de ratos tratados com ALA. A razão entre o aumento do nível de 8-oxodGuo e o de 5OHdCyd (razão $=3,6$ ) é muito próxima à determinada no DNA de timo de bezerro (razão: 4,0). Isso indica o envolvimento de radicais $\cdot \mathrm{OH}$ ou espécies reativas de oxigênio relacionadas, produzidas via reações como a de Fenton, também nas reações de oxidação do DNA mediadas pelo ALA in vivo. De fato, também puderam ser detectadas várias outras bases oxidadas, características do ataque do radical $\cdot \mathrm{OH}$ ao $\mathrm{DNA}^{137}$ (Figura 2).

As formações de 8-oxodGuo e de 2,6-diamino-4-hidroxi-5formamidopiridina (FapyGua) podem ser racionalizadas em termos da adição inicial de ${ }^{\circ} \mathrm{OH}$ ao átomo $\mathrm{C} 8$ da guanina, seguidas pela respectiva oxidação e redução do radical resultante 8-hidroxi-7,8dihidroguanil. 8-Oxo-7,8-dihidro-2'-desoxiadenosina (8-oxodAdo) é produzida a partir da adenina através de um processo similar envolvendo a oxidação de um radical transiente 8-hidroxi-7,8dihidroadenil. A abstração do hidrogênio da timina pelo ${ }^{\circ} \mathrm{OH}$ dá origem ao radical centrado no metil, o qual reage com $\mathrm{O}_{2}$ produzindo 5-(hidroxi-metil)uracila (5-HMUra) e 5-formiluracila (5-ForUra). A 5-hidroxicitosina (5-OHCyt) é produzida pela adição consecutiva de 'OH e uma molécula de oxigênio à dupla ligação C5-C6 da citosina. Isso leva à formação de uma mistura de isômeros cis e trans de 5,6dihidroxi-5,6-dihidrocitosina (citosina glicóis). Subseqüentemente, citosina glicóis podem ser convertidos tanto em 5-OHdCyt ou uracil glicóis através de desidratação e deaminação, respectivamente. A desidratação de uracil glicóis origina 5-hidroxiuracila (5-OHUra) ${ }^{137}$.

Os mecanismos que poderiam aumentar os riscos de desenvolvimento do processo carcinogênico em relação ao aumento de outras bases oxidadas são semelhantes àqueles já descritos para a 8oxodGuo. Apesar de haver mais estudos referentes à mutagenicidade e ao reparo da 8-oxodGuo, as outras bases modificadas também poderiam levar a mutações, sendo que vários sistemas de reparo para algumas das lesões também já foram descritos ${ }^{138-143}$.

Já é um consenso que eventos mutacionais estão na origem do processo de desenvolvimento do câncer. Tem sido proposto que um fenótipo mutante pode estar envolvido em alguns pontos nos vários estágios do processo carcinogênico ${ }^{144-147}$. Este modelo foi confirmado pela associação entre o câncer coloretal hereditário e defeitos em genes que codificam para proteínas de reparo "mismatch"148,149. O impedimento dos mecanismos de reparo dos erros de replicação do DNA pode originar uma instabilidade genética intrínseca. Esse passo inicial da carcinogênese pode levar a mutações em oncogenes ou inativação de genes supressores de tumor alterando o controle de crescimento celular. Um ataque oxidativo a genes envolvidos no reparo de bases oxidadas como a 8-oxodGuo poderia participar no processo do câncer, iniciando ou acelerando certos passos pelo aumento da instabilidade genética de uma célula em particular ${ }^{150,151}$.

\section{Danos ao DNA promovidos por ácido 4,5-dioxovalérico}

Vários aldeídos, como o $\mathrm{MDA}^{152-154}$,acetaldeído ${ }^{155,156}$ compostos dicarbonílicos ${ }^{157,158}$ e uma série de aldeídos $\alpha-\beta$ insaturados ${ }^{159-167}$, têm sido estudados quanto a sua reatividade em relação ao DNA e têm sido identificados como eficientes agentes alquilantes de bases. $\mathrm{Na}$ maioria dos casos, o principal sítio reativo é o grupo amino exocíclico da guanina que é a base mais nucleofílica do DNA. Considerando esses estudos, o produto final da oxidação do ALA, o DOVA, sendo um $\alpha$-cetoaldeído, poderia também formar adutos com os grupos amino das bases do DNA. De fato, a partir dos experimentos realizados pudemos estabelecer o possível mecanismo pelo qual o DOVA poderia lesar o DNA ${ }^{164,168}$. Utilizando a dGuo como modelo, foi demonstrado que o DOVA é capaz de se adicionar ao grupo amino exocíclico do anel de guanina (Esquema 2). Inicialmente foram detectados dois adutos principais (1 e 2) produzidos a partir da formação de uma base de Schiff entre o átomo de nitrogênio $N^{2}$ exocíclico da guanina e o carbono C4 do DOVA. Entretanto, a relativa instabilidade da base de Schiff dos adutos DOVA-dGuo levou a uma reversão a dGuo e DOVA por hidrólise. Deste modo, a caracte-<smiles>[12CH]n1c(=O)[nH]c2c(=O)[nH]c(N)nc21</smiles>

8-oxodGuo<smiles>Nc1ncnc2c1[nH]c(=O)n2[Te]</smiles>

8-oxodAdo<smiles>Nc1nc(N)c(NC=O)c(=O)[nH]1</smiles>

FapyGua<smiles>[R]n1cc(O)c(N)nc1=O</smiles>

5-OHCyt $(\mathrm{R}=\mathrm{H})$

$5-$ OHdCyd $(R=d R)$<smiles>O=Cc1c[nH]c(=O)[nH]c1=O</smiles>

5 -ForUra<smiles>[R]n1cc(O)c(=O)[nH]c1=O</smiles>

5-OHUra $(\mathrm{R}=\mathrm{H})$

$5-$ OHdUrd $(R=d R)$<smiles>O=c1[nH]cc(CO)c(=O)[nH]1</smiles>

5-HMUra<smiles>Nc1nc(=O)[nH]c(O)c1O</smiles>

Citosina glicóis 


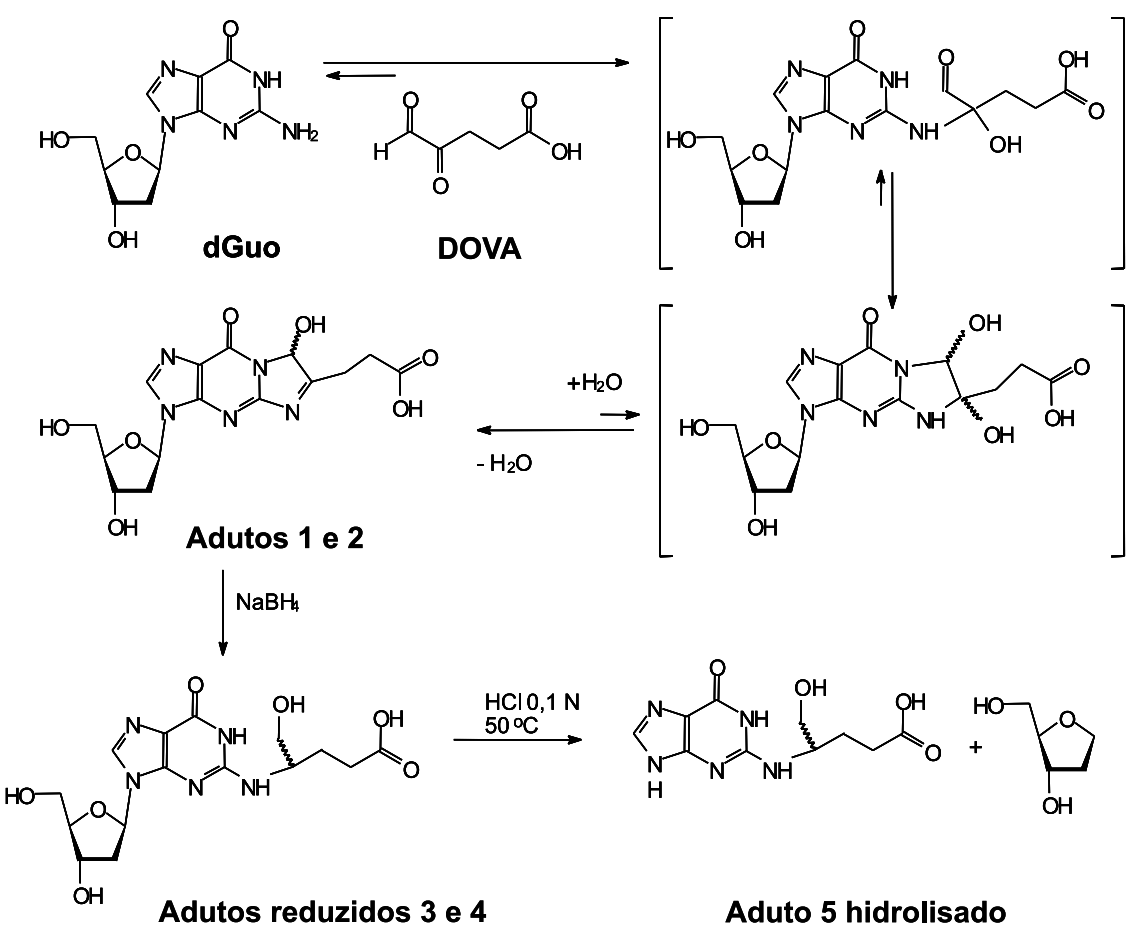

Esquema 2. Estrutura e formação dos adutos DOVA-dGuo e seus produtos de redução

rização dos adutos DOVA-dGuo por análises em ressonância magnética nuclear (RMN) e espectroscopia de massas (MS) requereu a redução preliminar da base de Schiff em um grupo amina secundária mais estável. O mesmo procedimento foi realizado para a detecção do aduto no DNA isolado de timo de bezerro.

Os adutos reduzidos 3 e 4 foram analisados separadamente por cromatografia gasosa/espectroscopia de massas (GC/MS) após trimetilsililação. Os espectros de massa obtidos para os derivativos TMS de ambos os adutos DOVA-dGuo reduzidos foram muito similares, sugerindo, juntamente com o espectro de absorbância em luz ultravioleta, que 3 e 4 eram diastereoisômeros. A identificação do pico a $\mathrm{m} / \mathrm{z}=653$ como o íon molecular foi confirmado pela observação da perda do fragmento metil $(\mathrm{m} / \mathrm{z}=638)$ que representa a fragmentação clássica para compostos trimetilsililados. Um íon a m/z=393 (e seu derivado demetilado) correspondente à base protonada do nucleosídeo também estava presente entre os principais picos do espectro de massa. O peso molecular de 653 Da pode ser explicado pela adição de quatro grupos trimetilsilil à 3 e 4 e uma perda adicional de uma molécula de água.

A partir da análise por espectroscopia de massas utilizando ionização por "electrospray" (ESI-MS), pudemos inferir o peso molecular de 3 e 4 como sendo 383. Isso poderia ser entendido como um aduto DOVA-dGuo 1:1 que perdeu uma molécula de água e ganhou quatro átomos de hidrogênio. Esse último ganho é consistente com a redução da base de Schiff e do grupo carboxílico restante do DOVA. A perda de uma molécula de água ocorre devido à formação da base de Schiff. De fato, os dados do infravermelho mostraram que um grupo carboxilato está presente na molécula $\left(v=1605 \mathrm{~cm}^{-1}\right)$. Duas bandas de vibração foram observadas na região da carbonila: $v\left(\mathrm{~cm}^{-1}\right) 1682\left(\mathrm{C}=\mathrm{O}\right.$ da guanina), $1605\left(-\mathrm{COO}^{-}\right)$. Esses resultados sugerem uma esterificação intramolecular ou uma amidação do grupo carboxilato como uma explicação alternativa para a perda de água na formação de 3 e 4 . A estrutura proposta também confere com as características dos espectros dos adutos reduzidos 3 e 4 obtidos na análise por ${ }^{1} \mathrm{H}-\mathrm{RMN}$. Os espectros foram quase idênticos, como já havia sido também observado nas análises por espectroscopia de massas. As diferenças nos respectivos deslocamentos químicos dos prótons de 3 e 4 foram menores que $0,05 \mathrm{ppm}$ e a multiplicidade de todos os sinais foram idênticos para ambos os compostos. Observou-se também sinais correspondentes aos prótons da hidroxila não trocáveis da 2'-desoxirribose, inferidos pelo experimento de COSY $2 \mathrm{D}$, confirmando que 3 e 4 são derivados de nucleosídeo. A similaridade entre as características do espectro de ' $\mathrm{H}-\mathrm{RMN}$ do anel da 2'desoxirribose da dGuo e do espectro dos adutos 3 e 4 também foi encontrada no espectro de ${ }^{13} \mathrm{C}-\mathrm{RMN}$.

Deste modo, os adutos 3 e 4 foram caracterizados como dois diastereoisômeros dos produtos reduzidos da base de Schiff produzida pela adição do DOVA ao grupo $N^{2}$-amino da dGuo como proposto no esquema 2. Um intermediário dessa reação pode exibir uma estrutura diol como os adutos gerados pela reação do glioxal e seus derivados com compostos contendo guanina ${ }^{157,158}$. No entanto, no caso do DOVA, ocorre a desidratação da ligação -NH-C-OH-, levando à formação da base de Schiff. Essa reação foi evidenciada pela formação de adutos similares em DNA isolado de timo de bezerro incubado com DOVA. Isso indica que o envolvimento do grupo amino $N^{2}$ exocíclico da guanina no pareamento com a citosina, não impede a adição nucleofílica ao grupo cetona do DOVA. A relativa instabilidade dos adutos DOVA-dGuo poderia ser compensada pela eficiência da reação de adição do DOVA a dGuo. Além disso, é provável que a estrutura de dupla fita do DNA estabilize os adutos formados. O nome oficial do aduto reduzido formado entre o DOVA e a dGuo é ácido 4-[ [9- (2-desoxi- $\beta$-D-eritro-pentofuranosil)- 6,9dihidro-6-oxo-1H-purina-2-il] amino] -5-hidroxivalérico ${ }^{164,168}$.

Outros aldeídos que também induzem formação de bases de Schiff no DNA são conhecidos mutagênicos ${ }^{169,170}$. Glioxal e outros compostos $\alpha$-dicarbonílicos também são mutagênicos ${ }^{171}$ e eficientes agentes alquilantes do grupo amino $N^{2}$ exocíclico da guanina ${ }^{157,158}$. O acetaldeído é capaz de promover aberrações cromossômicas em células de mamíferos em cultura ${ }^{170,172}$. Também deve ser enfatizado que os adutos acetaldeídos de guanina com estrutura de base de Schiff 
foram recentemente detectados em células sangüíneas de humanos e podem estar relacionados com os efeitos carcinogênicos atribuídos ao álcool ${ }^{156}$.

Adutos estáveis formados a partir do crotonaldeído, também já foram detectados in vivo, sendo, entretanto, reparados lentamente ${ }^{173}$. Os etenoadutos produzidos a partir de diversos compostos carcinogênicos e produtos da lipoperoxidação, como certos aldeídos, também são capazes de produzir substituições de bases em DNA. In vitro as eteno bases são reparadas por DNA glicosilases de mamífe$\operatorname{ros}^{174-178}$ e por extratos de células de ratos ${ }^{179}$ ou humanas ${ }^{180}$. Etenoaduto de timina é removido por uma DNA glicosilase humana específica para timina ${ }^{176}$. A inibição dessas enzimas de reparo ou a falta de expressão em certos tipos celulares leva ao acúmulo ou persistência de alguns etenoadutos em DNA de alguns tecidos e células de roedores ${ }^{181,182}$.

A formação e detecção de adutos promovidos por ROS e por produtos da peroxidação lipídica têm sido cada vez mais estudadas ${ }^{183,184}$ e sua correlação com a carcinogênese cada vez mais relevante $^{185-188}$. Deste modo, a formação de adutos entre o DOVA e a dGuo constitui mais um dano ao DNA, entre os promovidos po ALA, poderiam levar à mutagênese ${ }^{164}$.

\section{Danos ao DNA promovidos por derivados de dihidropirazina}

Durante a biossíntese do grupo heme, o ALA sofre uma dimerização com a eliminação de duas moléculas de água originando o porfobilinogênio ${ }^{189}$. Entretanto, como reportado em diversos estudos sobre os produtos da condensação cíclica do ALA, esta não é a única forma pela qual duas moléculas de ALA podem condensar para produzir produtos cíclicos ${ }^{190}$. Foi observado que a dimerização cíclica do ALA a pH 5-6 gera exclusivamente um derivado de dihidropirazina, o ácido 3,6-dihidropirazina-2,5-dipropanóico (DHPY) (Esquema 3).Vários estudos mostram que alguns derivados de dihidropirazinas podem causar quebras de fita em DNA plasmidial ${ }^{191}$ pela geração de radicais $\mathrm{OH}$ e centrados no carbono ${ }^{192,193}$. Duas moléculas de ALA condensam através de uma reação amino-carbonil para formar o DHPY, seguida por uma oxidação mediada por $\mathrm{Cu}^{2+}$ gerando o ácido pirazina 2,4-dipropanóico (PY) acompanhada pela redução do $\mathrm{Cu}^{2+} \mathrm{a} \mathrm{Cu}^{+} \mathrm{e}$ a formação de $\mathrm{H}_{2} \mathrm{O}_{2}$ pela dismutação do ânion superóxido. $\mathrm{OH}_{2} \mathrm{O}_{2}$ reage subseqüentemente com o $\mathrm{Cu}^{+}$para formar $\mathrm{OH}^{194} \mathrm{e} / \mathrm{ou}$ um radical cripto-OH como o complexo $\mathrm{Cu}^{+}$-peróxido (Esquema 3), causando os danos ao DNA ${ }^{195}$. Esses danos podem ser facilitados pela alta afinidade do cobre ao DNA ${ }^{194}$.

Nossos trabalhos demonstraram que o DHPY é capaz de induzir quebras no DNA plasmidial e aumento da formação de 8-oxodGuo em dGuo. Esses danos foram diminuídos pela adição de batocuproina, um quelante de metais, das poliaminas espermina ou espermidina ou de enzimas antioxidantes como a SOD e a catalase ${ }^{196}$. Considerando que concentrações micromolares de DHPY são suficientes para induzir danos ao DNA, a formação de DHPY constituiria outro mecanismo adicional indireto pelo qual o acúmulo de ALA poderia lesar o DNA, levando a mutações e possíveis alterações celulares que levariam ao estabelecimento de um processo carcinogênico.

\section{DANOS AO DNA MITOCONDRIAL PROMOVIDOS POR ÁCIDO 5-AMINOLEVULÍNICO}

O DNA mitocondrial pode ser considerado um alvo significativo das espécies reativas de oxigênio ${ }^{197}$.

Yakes e Van Houten ${ }^{198}$ relataram que os danos ao DNA mitocondrial são mais extensos e persistem por mais tempo que os danos ao DNA nuclear em fibroblastos humanos submetidos a estresse

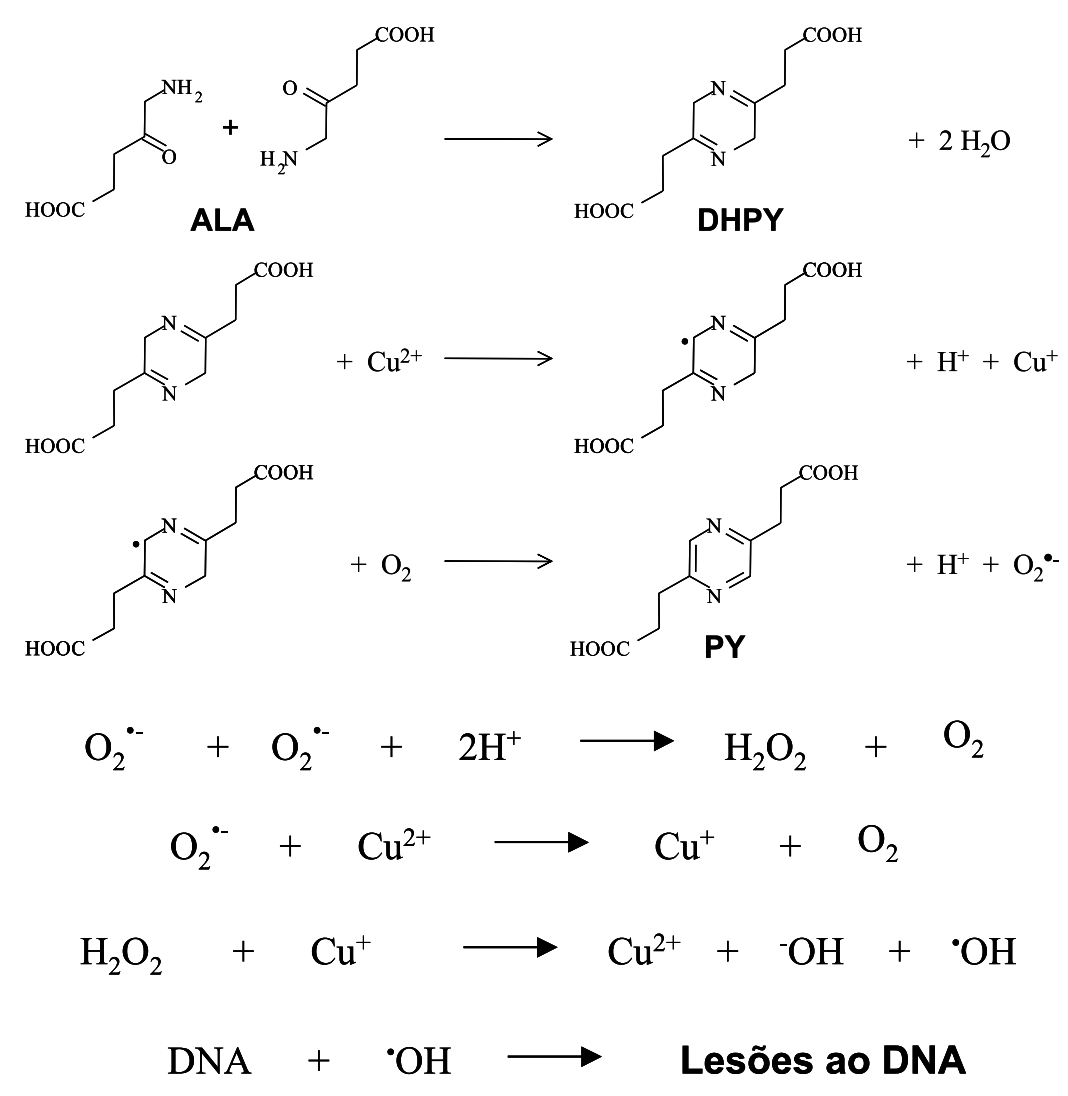

Esquema 3. Mecanismos propostos de indução de lesões ao DNA mediada pelo ácido 3,6-dihidropirazina-2,5-dipropanóico (DHPY) na presença de cobre 
oxidativo gerado por $\mathrm{H}_{2} \mathrm{O}_{2}$. Estudos de Ames et al. ${ }^{199}$ revelaram que o DNA mitocondrial de ratos mais velhos apresenta mais danos que o de ratos mais jovens.

Salazar e Van Houten ${ }^{200}$ relataram também um aumento nos danos ao DNA mitocondrial em células tratadas com $\mathrm{H}_{2} \mathrm{O}_{2}$. Já foi demonstrado também que os produtos da peroxidação lipídica podem atacar o DNA mitocondrial ${ }^{201}$ e que este é mais susceptível que o nuclear à alquilação ${ }^{202,203}$. Niranjan et al. ${ }^{204}$ demonstraram que a administração do carcinógeno hepático aflatoxina $\mathrm{B} 1$ a ratos resulta em ligação covalente ao DNA mitocondrial do fígado em concentrações de três a quatro vezes maiores que ao DNA nuclear, permanecendo inalterada mesmo após 24 horas.

Esses dados indicam que o DNA mitocondrial seria mais susceptível que o nuclear ao ataque por ROS. De fato, Richter et al. ${ }^{205}$ relataram maior quantidade de 8-oxodGuo em DNA mitocondrial em relação ao nuclear após tratamento de mitocôndrias isoladas com raios $\gamma$. Várias são as razões para se acreditar na maior susceptibilidade do DNA mitocondrial aos danos oxidativos; a mitocôndria consome mais de $90 \%$ do oxigênio celular e a cadeia respiratória é uma fonte contínua de $\mathrm{ROS}^{206}$; o DNA mitocondrial não possui histonas, estando mais susceptível ao ataque por ROS que o DNA nuclear. O genoma mitocondrial possui poucas seqüências não codificadoras e não possui introns. Além disso, a mitocôndria é menos eficiente no reparo de danos ao DNA e erros de replicação que o núcleo ${ }^{207}$.

A mitôcondria parece não possuir reparo por excisão de nucleotídeos ${ }^{203,208}$. Entretanto é capaz de reparo por excisão de ba$\operatorname{ses}^{209}$. Já foram identificadas três uracil DNA glicosilases ${ }^{210-212}$, duas endonucleases específicas para sítios apurínicos/apirimidínicos e uma DNA ligase ${ }^{213}$ que podem ser responsáveis pelos baixos níveis de lesões oxidativas em condições fisiológicas ${ }^{214}$. Já foi identificada uma endonuclease específica para danos oxidativos em mitocôndria de fígado de ratos, que é específica para 8-oxodGuo e sítios abásicos no DNA dupla fita ${ }^{215}$. Estudos imunológicos localizaram o produto do gene $O G G 1$ humano em mitocôndrias ${ }^{216}$. Myers et al. ${ }^{203}$ demonstraram que $O^{6}$-metil-2 $2^{\prime}$-desoxiguanosina pode ser reparada na mitocôndria por uma proteína codificada no núcleo e transportada para mitocôndria.

Outros estudos também sugerem que a mitocôndria pode ter reparo por recombinação; DNA mitocondrial de hamster foi capaz de reparar lesões induzidas por cisplatina ${ }^{217}$, ensaios in vitro também apresentaram recombinação entre plasmídios utilizando extratos de proteína de mitocôndrias humanas ${ }^{218}$.

Vários estudos correlacionam as alterações funcionais e estruturais na mitocôndria e os danos ao DNA ao envelhecimento celular ${ }^{219}$ e com o processo carcinogênico ${ }^{197,220}$. Alterações na estrutura, nas funções e no número de mitocôndrias, conjuntamente com altas taxas glicolíticas já foram reportadas em algumas linhagens celulares tumorais ${ }^{221}$. A toxicidade de agentes oxidantes sobre a mitocôndria e seu DNA também tem sido relacionada ao processo carcinogênico ${ }^{198,200}$. Outros fatores como a reação preferencial de carcinógenos com DNA mitocondrial em relação ao nuclear ${ }^{201,202,204,205}$ e a relação direta entre a potência carcinogênica de uma série de $N$-hidroxiacetilaminofluorenos em ratos e sua capacidade de afetar a fosforilação oxidativa ${ }^{222}$, também têm indicado que a mitocôndria pode exercer um papel importante nos danos celulares quimicamente induzidos e relacionados com o o desenvolvimento do câncer.

Já foi demonstrado que o ALA também é capaz de alterar as funções mitocondriais através da produção de $\operatorname{ROS}^{79,85,86}$ e biópsias de fígado de pacientes portadores de porfirias apresentaram alterações estruturais em mitocôndrias ${ }^{89}$.

Dentro deste contexto, o maior número de lesões encontradas no DNA mitocondrial em relação ao nuclear em células tratadas com ALA (Onuki et al., em preparação), indica que danos à mitocôndria também poderiam contribuir para os mecanismos envolvidos na maior incidência de HCC em pacientes com AIP.

Várias são as hipóteses para explicar como as mutações no DNA mitocondrial poderiam contribuir para o processo carcinogênico ${ }^{197,220}$. Entretanto, no caso do acúmulo do ALA, a hipótese mais plausível seria a conexão entre a deficiência respiratória de mitocôndrias mutantes e a liberação aumentada de ROS e de produtos secundários da peroxidação lipídica para o citossol, expondo o núcleo e outros componentes celulares a essas espécies citotóxicas. Aumentando o estresse oxidativo, as mutações no DNA mitocondrial, induzidas por agentes carcinogênicos, poderiam amplificar os danos ao DNA nuclear e aumentar a probabilidade de ativação de oncogenes ou inativação de genes supressores de tumor ${ }^{197}$. Mutações mitocondriais que aumentam o estresse oxidativo, também poderiam influenciar a proliferação celular através de alterações no armazenamento de cálcio ou na sinalização celular ${ }^{223}$.

\section{MUTAGENICIDADE DO ALA E DO DOVA}

Diversos agentes endógenos e exógenos podem levar a danos ao DNA, como modificações de bases, quebras em cromossomos, deleções, inversões, etc. ${ }^{128,184}$. As ROS e os aldeídos produzidos durante a peroxidação lipídica são considerados agentes importantes na indução de lesões ao DNA $^{224}$ que podem levar a mutações que têm sido relacionadas com o desenvolvimento do câncer ${ }^{128,183,188,225}$.

A célula possui inúmeros sistemas enzimáticos responsáveis pelo reparo de lesões ocorridas no DNA, inclusive as oxidativas ${ }^{139,142,226}$. Entretanto, se houver um excesso de lesões, há uma maior probabilidade de alterações no DNA, como mudanças conformacionais na sua estrutura, bloqueio e erros durante a replicação. Essas lesões podem levar ao aparecimento de mutações, ou seja, à incorporação errônea de bases no DNA que pode ser perpetuada na divisão celular.

Já é um consenso que eventos mutacionais estão na origem do processo de desenvolvimento do câncer. Tem sido proposto que um fenótipo mutante pode estar envolvido em alguns pontos nos vários estágios do processo carcinogênico ${ }^{144-147}$. Mutações em oncogenes ou em genes supressores de tumor, alteram o controle do crescimento celular, iniciando ou acelerando certos passos que contribuem para o estabelecimento de um tumor ${ }^{147}$. Danos a genes envolvidos no reparo de bases oxidadas também podem aumentar a instabilidade genética da célula, contribuindo para o processo carcinogênico ${ }^{150,151}$.

Como já descrito, o ALA promove inúmeras lesões ao DNA, como quebras de fita em DNA plasmidial ${ }^{106}$ e o aumento de bases oxidadas do DNA in vitro ${ }^{137}$ e in vivo ${ }^{108}$; seu produto final, o aldeído DOVA, também pode reagir com dGuo, formando adutos de DNA. Já foi relatado que o ALA é capaz de induzir aberrações cromossômicas em hepatócitos de ratos ${ }^{227}$ e o potencial carcinogênico do ALA tem recebido atenção adicional com a utilização do ALA como um agente fototerápico ${ }^{228-231}$.

Várias metodologias têm sido desenvolvidas para determinar o potencial carcinogênico de diversas substâncias; um dos testes mais empregados é o Teste de mutagenicidade por Salmonella/ microsuspensão, mais conhecido como Teste de Ames.

O Teste de Ames, desenvolvido por Ames e colaboradores ${ }^{232}$, consiste basicamente na utilização de linhagens da bactéria Salmonella typhimurium, para detectar mutações causadas por diversos agentes físicos e químicos. Conforme a linhagem utilizada, o ensaio é capaz de detectar diferentes eventos mutacionais: mutações por substituição de pares de bases, por mudança no quadro de leitura ou por deleções ${ }^{233}$. As linhagens utilizadas podem ser modificadas de modo a torná-las mais sensíveis, permeáveis a moléculas grandes e também mais suscetíveis a mutações devido a modificações genéticas que levam à deficiência de sistemas de reparo de lesões ao DNA ${ }^{234}$. 
O potencial carcinogênico das substâncias é determinado pela presença de mutações no DNA da bactéria. Essas alterações são detectadas através de mutações reversas da mutação no operon da histidina que torna a bactéria auxotrófica para histidina. Se o agente for capaz de reverter essa mutação, a bactéria, dita revertente, é capaz de crescer sem a presença de histidina.

Diversas cepas de Salmonella typhimurium são utilizadas no Teste de Ames. Cada uma possui características próprias que as tornam mais ou menos suscetíveis aos diversos agentes químicos e/ou físicos, sendo capazes de detectar diferentes tipos de mutações. As cepas utilizadas no Teste de Ames também detectam agentes que causam mutações indiretas no DNA através da utilização de sistema de ativação metabólica (S9), que consiste num extrato de fígado de rato.

A função primordial das diferentes linhagens é detectar e caracterizar os danos ao DNA, sem que seja considerado um modelo de processos de mutações operantes em células de mamíferos. A correlação que se pode fazer é que os eventos mutacionais ocorridos na bactéria e em células de mamíferos são ambos decorrentes de danos ao DNA celular ${ }^{233}$.

As linhagens TA102 e TA104 carregam a mutação nonsense (TAA-) no sítio de reversão que está presente em uma única cópia no cromossomo (TA104), ou em múltiplas cópias em plasmídios (TA102). Ambas as linhagens foram originalmente desenvolvidas para detectar peróxidos e outros oxidantes. Vários agentes oxidantes mutagênicos já foram testados como raios-X, bleomicina, $\mathrm{H}_{2} \mathrm{O}_{2}$ e outros hidroperóxidos; aldeídos como formaldeído, glioxal, glutaraldeído, malonaldeído e psoralenos ${ }^{169,235,236}$. Esses compostos são pouco ou não são detectados em linhagens que contêm os pares C:G no sítio de reversão.

Outro teste utilizado para determinar a mutagenicidade de compostos é o Cromoteste, que detecta danos ao DNA através da verificação da indução da resposta SOS.

O sistema de resposta SOS ("error-prone repair") ${ }^{237}$ constitui um dos vários sistemas de reparo atuantes na célula bacteriana: reparo por excisão de bases, reparo por excisão de nucleotídeos ${ }^{238}$, fotorreativação e reparo por recombinação ${ }^{239}$.

Esse sistema de reparo possui uma importância considerável no aparecimento de mutações, uma vez que é induzido por lesões ${ }^{240} \mathrm{e}$ leva à incorporação errônea de bases no DNA como um mecanismo para evitar o bloqueio da replicação, garantindo a sobrevivência da bactéria.
Deste modo, as mutações no DNA bacteriano promovidas pelos diferentes compostos podem ser acessadas através da indução da resposta SOS. A linhagem Escherichia coli PQ37 foi desenvolvida como organismo indicador dessa indução. A detecção ocorre através da presença do gene estrutural da $\beta$-galactosidase ( $\beta$-gal) sob o controle do operador do gene sfiA, um dos responsáveis pela filamentação bacteriana, uma das respostas SOS. Na E.coli PQ37, a síntese de $\beta$-gal só ocorre quando o gene sfiA é induzido, uma vez que o gene lac $Z$ normal desta cepa foi deletado. A E. coli PQ37 possui ainda as mutações $u v r$ A e $r f a$ que aumentam a sua sensibilidade, a primeira por torná-la deficiente em reparo por excisão, e a segunda por permitir a entrada de substâncias químicas normalmente não difusíveis em uma célula de E.coli selvagem.

Diversos compostos que também induzem a formação de adutos em DNA já foram testados quanto a sua mutagenicidade pelo Teste de Ames e pelo Cromoteste. Crotonaldeído promoveu o crescimento de 940 revertentes/mmol em linhagem TA104 ${ }^{169}$ e de 1952 revertentes/ mmol em TA100 141 e também induziu resposta SOS no Cromoteste em PQ37 ${ }^{161}$. O tratamento de TA104 com 2-hexenal induziu $\quad 460$ revertentes $/ \mu_{\mathrm{mol}}{ }^{169}$ e 980 revertentes $/ \mathrm{mmol}$ na linhagem TA $100^{241}$.

A mutagenicidade do ALA e do DOVA foi detectada na linhagem de S. typhimurium TA104 sem ativação metabólica e o ALA foi capaz de induzir a resposta SOS em E. coli PQ37242,243.

A Figura 3 resume os possíveis diferentes mecanismos de lesões ao DNA promovidas por ALA relatados nesta revisão, que poderiam levar a mutações, constituindo o passo inicial de promoção de um processo carcinogênico. Esses processos poderiam ser conectados à maior incidência de HCC em pacientes sintomáticos portadores de AIP.

\section{CONCLUSÕES}

O ácido 5-aminolevulínico, o primeiro precursor do grupo heme, acumula-se principalmente no fígado de pacientes portadores de AIP, em concentração que pode alcançar oito ou mais vezes que a do nível plasmático ${ }^{60}$. Devido à produção de ROS durante sua oxidação, o ALA pode ser visto como um pró-oxidante endógeno ${ }^{78}$, causando danos a diversas biomoléculas ${ }^{4,84}$. De fato, há várias evidências do seu potencial pró-oxidante, principalmente na presença de metais de transição $0^{4,84}$. Deste modo, o ALA pode estar relacionado às manifestações clínicas da $\mathrm{AIP}^{77,108}$, inclusive à maior incidência

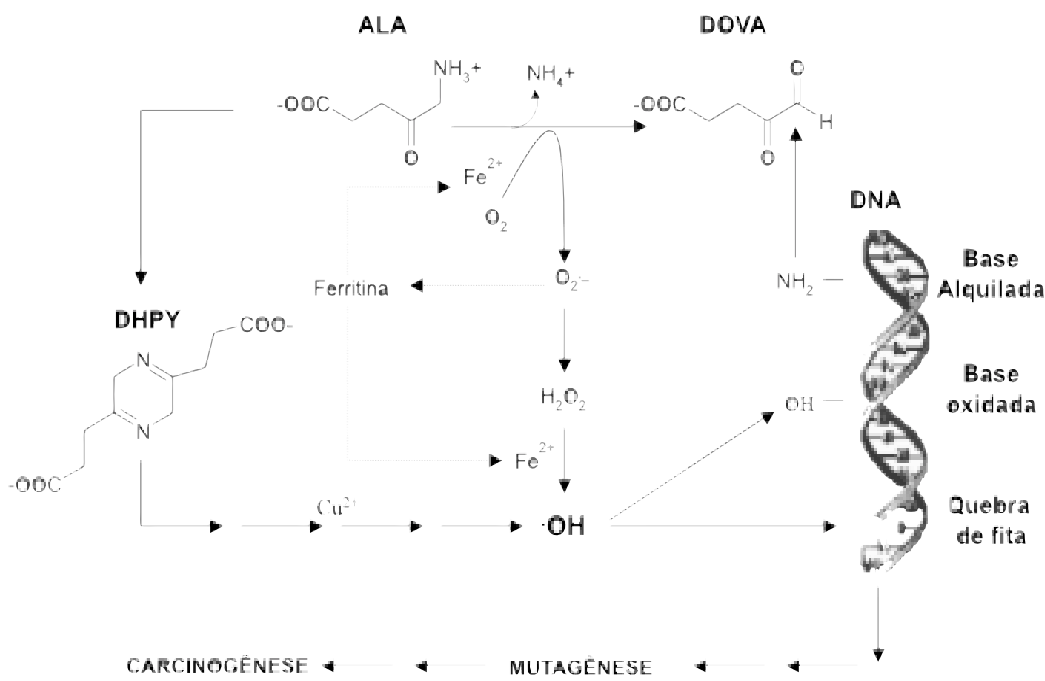

Figura 3. Possíveis mecanismos de danos ao DNA induzidos por ácido 5-aminolevulínico (ALA) associados a sua mutagenicidade 
de $\mathrm{HCC}^{62,64-67}$ uma vez que a produção de ROS tem sido constantemente relacionada à iniciação e à promoção do câncer ${ }^{128,244-247}$.

O ALA possui potencial pró-oxidante e é capaz de promover lesões ao DNA ${ }^{248}$, como quebras de fita em DNA plasmidial ${ }^{106}$, aumento dos níveis de várias bases oxidadas in vitro e in vivo ${ }^{108,137}$, além da formação de adutos entre a dGuo e o DOVA, produto final de oxidação do $\mathrm{ALA}^{164} \mathrm{e}$ das lesões promovidas pela dihidropirazina, produto da dimerização do $\mathrm{ALA}^{196}$. O ácido 5-aminolevulínico e o DOVA também foram capazes de induzir aumento de mutagenicidade em S. typhimurium TA104 e resposta SOS em E. coli PQ37242,243.

Considerando todos esses danos ao DNA promovidos pelo ALA e seus derivados, podemos estabelecer uma possível conexão entre a concentração elevada de ALA, os metais de transição, aldeídos e o processo de displasia celular ${ }^{248}$. É bem documentado que íons de metais de transição, como o ferro, podem exercer um papel importante na geração de quantidades deletérias de ROS causando, deste modo, mudanças patológicas. Vários casos de câncer de fígado têm sido relatados em pacientes com acúmulo de ferro. Deste modo, o aumento da geração de ROS pode levar a danos oxidativos e ser potencialmente carcinogênico ${ }^{128,225,244,245}$. DNA de fígado pode ser um alvo crucial para as ROS geradas pela oxidação do ALA catalisada por metais e os íons de $\mathrm{Fe}^{2+}$ podem intensificar os danos ao DNA induzidos por ALA in vivo. $\mathrm{O}$ grande acúmulo de $\mathrm{Fe}^{3+}$-ferritina observado no citoplasma de hepatócitos de pacientes com AIP $^{89}$ pode ser uma fonte potencial de íons $\mathrm{Fe}^{2+}$ pois o $\mathrm{O}_{2}^{--}$e o radical enoil gerados pelo ALA podem liberar $\mathrm{Fe}^{2+}$ da ferritina ${ }^{103,104}$, e também, possivelmente, cobre da ceruloplasmina.

Anormalidades no metabolismo das porfirinas, que inclui o acúmulo de ALA, foram previamente implicadas na patogênese de $\mathrm{HCC}^{65,249}$. Bengtsson e Hardell ${ }^{64}$ propuseram duas hipóteses para explicar esta associação: primeiro, uma mutação de ponto no locus do gene da porfobilinogênio deaminase, presente no braço longo do cromossomo 11, pode estar ligada com a ativação do oncogene responsável pelo desenvolvimento do HCC. Segundo, as porfirinas por si próprias poderiam ser carcinogênicas.

Considerando os resultados apresentados referentes às lesões ao DNA, uma terceira proposta de bases moleculares para explicar as recentes associações do HCC com a AIP pode agora ser sugerida ${ }^{248,250}$.

Em AIP, o ALA é superproduzido primariamente como resultado da baixa atividade da PBGD (Esquema 1)²; grandes quantidades de ALA são acumuladas cronicamente no fígado, provavelmente na mitocôndria, durante anos ${ }^{88}$; o ferro cronicamente acumulado nos hepatócitos de pacientes com AIP participa da oxidação do ALA, o ALA também pode sofrer dimerização cíclica, formando o DHPY, conjuntamente esses sistemas produzem $\mathrm{H}_{2} \mathrm{O}_{2}{ }^{78}$ que leva à geração de radicais ${ }^{\circ} \mathrm{OH}$ in situ promovendo o ataque ao material genético (DNA nuclear e/ou mitocondrial) levando à formação de:

(i) hidroxilação de bases;

(ii) quebras de fita;

(iii) bases do DNA alquiladas pelo DOVA, gerando adutos.

Essas lesões ao DNA podem ser potencialmente mutagênicas, constituindo o primeiro passo para o estabelecimento de um processo carcinogênico (Figura 3).

Apesar das concentrações utilizadas nos experimentos serem da ordem de milimolar, devemos considerar que ainda não se determinou para cada tipo de célula e organela qual a quantidade de ALA realmente captada. Além disso, os experimentos realizados in vivo, com animais modelo, mostram os efeitos do tratamento com ALA por 15 dias; enquanto nos pacientes, os possíveis efeitos da alteração da concentração do ALA seriam provavelmente decorrentes de um tempo de exposição bem mais prolongado.

Em conclusão, níveis aumentados de ALA cronicamente, em pacientes com AIP, podem desempenhar um papel importante nos danos ao DNA. A formação de bases oxidadas e alquiladas poderia desencadear processos mutagênicos levando a um maior risco de desenvolvimento de um carcinoma hepatocelular nesses pacientes.

O conhecimento sobre a patogênese do câncer é um pré-requisito básico para a prevenção e tratamento do mesmo; o estudo do potencial pró-oxidante do ALA pode servir de modelo na tentativa de melhor compreender a participação das ROS e dos aldeídos nos danos ao DNA relacionados ao estabelecimento de um processo carcinogênico, tanto em AIP, quanto em outras doenças (Figura 4).

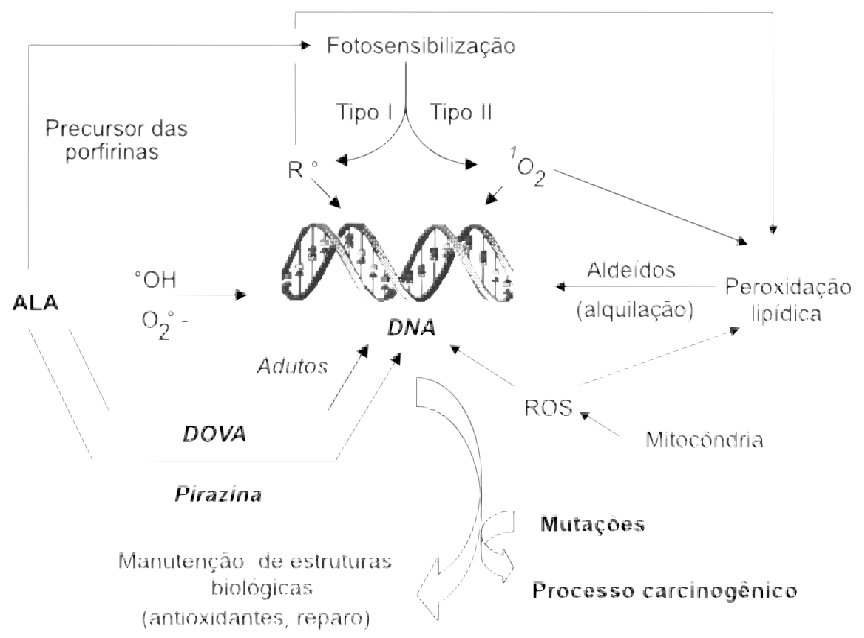

Figura 4. Participação do ALA na promoção de danos em DNA entre possiveis fontes endógenas de geração de espécies reativas de oxigênio e aldeídos

\section{AGRADECIMENTOS}

À Fundação de Amparo à Pesquisa do Estado de São Paulo (FAPESP), ao Conselho Nacional para o Desenvolvimento Científico e Tecnológico (CNPq), ao Programa de Apoio aos Núcleos de Excelência (PRONEX/FINEP), à Universidade de São Paulo/Comité Français d'Evaluation de la Coopération Universitaire avec le Brésil (USP-COFECUB/UC-23/96 e UC/98), ao Programa de Apoio ao Desenvolvimento Científico e Tecnológico (PADCT), à Pró-Reitoria de Pesquisa da Universidade de São Paulo, à Universidade de Buenos Aires, ao Fundo Bunka de Pesquisa-Banco Sumitomo-Mitsui, à University of Texas Medical Branch, à Companhia de Tecnologia de Saneamento Ambiental, ao Departamento de Bioquímica e ao Instituto de Química da Universidade de São Paulo. Pricila C. Teixeira é bolsista de iniciação científica da Pró-Reitoria de Pesquisa da USP. Dra. Janice Onuki é bolsista de pós-doutorado da FAPESP.

\section{REFERÊNCIAS}

1. Dailey, H. A.; J. Biol. Inorg. Chem. 1997, 2, 411.

2. Hindmarsh, J. T.; Clin. Chem. 1986, 32, 1255.

3. Gordon, N.; Brain Dev. 1999, 21, 373.

4. Bechara, E. J. H.; Medeiros, M. H. G.; Monteiro, H. P.; Hermes-Lima, M.; Pereira, B.; Demasi, M.; Costa, C. A.; Abdalla, D. S.; Onuki, J.; Werbin, H.; Di Mascio, P.; Quím. Nova 1993, 16, 385.

5. Kappas, A.; Sassa, S.; Galbraith, R. A.; Nordmann, Y. Em The Metabolic Basis of Inherited Diseases; Scriver, C. R.; Beudet, A. L.; Sly, W. S.; Valle, D., eds.; McGraw-Hill: New York, 1995; p 2103.

6. Andersson, C.; Bjersing, L.; Lithner, F.; J. Intern. Med. 1996, 240, 195

7. Batlle, A. M. d. C.; J. Photochem. Photobiol. B 1993, 20, 5.

8. Sassa, S.; Kappas, A.; J. Intern. Med. 2000, 247, 169.

9. de Verneuil, H.; Ged, C.; Boulechfar, S.; Moreau-Gaudry, F.; J. Bionerg. Biomembr. 1995, 27, 239.

10. Lindberg, R. L.; Porcher, C.; Grandchamp, B.; Ledermann, B.; Burki, K.; Brandner, S.; Aguzzi, A.; Meyer, U. A.; Nat. Genet. 1996, 12, 195. 
11. Phillips, J. D.; Jackson, L. K.; Bunting, M.; Franklin, M. R.; Thomas, K. R.; Levy, J. E.; Andrews, N. C.; Kushner, J. P.; Proc. Natl. Acad. Sci. U. S. A. 2001, 98, 259.

12. Warren, M. J.; Jay, M.; Hunt, D. M.; Elder, G. H.; Rohl, J. C.; Trends Biochem. Sci. 1996, 21, 229.

13. Loftus, L. S.; Arnold, W. N.; Br. Med. J. 1991, 303, 1589.

14. Arnold, W. N.; JAMA 1988, 260, 3042.

15. Bonkovsky, H. L.; Cable, E. E.; Cable, J. W.; Donohue, S. E.; White, E. C.; Greene, Y. J.; Lambrecht, R. W.; Srivastava, K. K.; Arnold, W. N.; Biochem. Pharmacol. 1992, 43, 2359.

16. Chisolm, J. J.; Sci. Am. 1971, 224, 15

17. Higashikawa, K.; Furuki, K.; Takada, S.; Okamoto, S.; Ukai, H.; Yussa, T.; Ikeda, M.; Ind. Health 2000, 38, 181.

18. Costa, C. A.; Trivelaro, G. C.; Pinto, A. M.; Bechara, E. J. H.; Clin. Chem. 1997, 43, 1196.

19. Nathanson, J. A.; Bloom, F. E.; Nature 1975, 255, 419.

20. Johnson, F. M.; Mutat. Res. 1998, 410, 123.

21. Hermes-Lima, M.; Pereira, B.; Bechara, E. J. H.; Xenobiotica 1991, 21, 1085.

22. Gurer, H.; Ercal, N.; Free Radical Biol. Med. 2000, 29, 927.

23. Alessio, L.; Foa, V. Em Industrial Chemical Series; Alessio, L.; Berlin, A.; Roy, R.; Boni, M., eds.; CECA: Luxemburg, 1983, p. 107.

24. Piomelli, S.; Seaman, C.; Zullow, D.; Curran, A.; Davidow, B.; Proc. Natl. Acad. Sci. U. S. A. 1982, 79, 3335.

25. Mitchell, G. A.; Lambert, M.; Tanguay, R. M. Em The Metabolic Basis of Inherited Diseases; Scriver, C. R.; Beudet, A. L.; Sly, W. S.; Valle, D., eds.; McGraw-Hill: New York, 1995, p. 1077.

26. Phaneuf, D.; Hadchouel, M.; Tanguay, R. M.; Brechot, C.; Ferry, N.; Biochem. Biophys. Res. Commun. 1995, 208, 957.

27. Sacks, G. H.; JAMA 1990, 264, 1290.

28. Tschudy, D. P.; Valsamis, M.; Magnussen, C. R.; Ann. Intern. Med. 1975, 83,851 .

29. Magnussen, C. R.; Levine, J. B.; Doherty, J. M.; Cheesman, J. O.; Tschudy, D. P.; Blood 1974, 44, 857.

30. Lannfelt, L.; Wetterberg, L.; Lilius, L.; Thunell, S.; Gellerfors, P.; Clin. Chim. Acta 1989, 183, 227.

31. Haeger, B.; Lancet 1958, ii, 606

32. Schreiber, W. E.; Fong, F.; Jamani, A.; Clin. Chem. 1994, 40, 1744.

33. Paz-Sendin, L.; Ledesma-Rivero, G.; Chalgub-Moreno, A. M.; AbrahanMarcel, E. A.; Berroa-Diaz, F.; Allen-Hilton, W.; Rev. Neurol. 2001, 32 , 96.

34. Andersson, C.; Tese de Doutorado; University of Umea and Primary Health Care Center, Arjeplog, Sweden, 1997.

35. Suarez, J. I.; Cohen, M. L.; Larkin, J.; Kernich, C. A.; Hricik, D. E.; Daroff, R. B.; Neurology 1997, 48, 1678 .

36. Beattie, A. D.; Goldberg, A. Em Porphyrins in human diseases; Doss, M.; Lahn, M., eds.; Basel: Krager, 1976, p. 245.

37. King, P. H.; Bragdon, A. C.; Neurology 1991, 41, 1300.

38. Lip, G. Y.; McColl, K. E.; Moore, M. R.; Br. J. Clin. Pract. 1993, 47, 38

39. Anderson, K. E.; Semin. Hematol. 1989, 26, 10.

40. Lamon, J. M.; Frykholm, B. C.; Herrera, W.; Tschudy, D. P.; J. Clin. Endocrinol. Metab. 1979, 48, 123.

41. Thunell, S.; Floderus, Y.; Henrichson, A.; Moore, M. R.; Meissner, P.; Sinclair, J.; J. Stud. Alcohol 1992, 53, 272.

42. Welland, F. H.; Hellman, E. S.; Gaddis, E. M.; Collins, A.; Hunter, G. W.; Tschudy, D. P.; Metabolism 1964, 13, 232.

43. Thunell, S.; Andersson, C.; Carlmark, B.; Floderus, Y.; Gronqvist, S. O.; Harper, P.; Henrichson, A.; Lindh, U.; Eur. J. Clin. Chem. Clin. Biochem. 1995, 33, 179.

44. Stein, J. A.; Tschudy, D. P.; Medicine (Baltimore) 1970, 49, 1.

45. Lip, G. Y.; McColl, K. E.; Goldberg, A.; Moore, M. R.; Br. Med. J. 1991, 302, 507.

46. McColl, K. E.; Wallace, A. M.; Moore, M. R.; Thompson, G. G.; Goldberg, A.; Clin. Sci. (Colch.) 1982, 62, 183.

47. Anderson, K. E.; Freddara, U.; Kappas, A.; Arch. Biochem. Biophys. 1982, 217, 597.

48. Rifkind, A. B ; Prim Care 1976, 3, 665

49. Kauppinen, R.; Timonen, K.; Mustajoki, P.; Ann. Med. 1994, 26, 31.

50. Doss, M.; Sixel-Dietrich, F.; Verspohl, F.; J. Clin. Chem. Clin. Biochem. 1985, 23, 505

51. Bonkowsky, H. L.; Tschudy, D. P.; Collins, A.; Doherty, J.; Bossenmaier, I.; Cardinal, R.; Watson, C. J.; Proc. Natl. Acad. Sci. U. S. A. 1971, 68, 2725 .

52. Mustajoki, P.; Nordmann, Y.; Arch. Intern. Med. 1993, 153, 2004.

53. Dover, S. B.; Graham, A.; Fitzsimons, E.; Moore, M. R.; McColl, K. E.; Lancet 1991, 338, 263.

54. Schuurmans, M. M.; Hoffmann, F.; Lindberg, R. L.; Meyer, U. A.; Hepatology 2001, 33, 1217.
55. Rogers, P. D.; Ann. Pharmacother 1997, 31, 365.

56. Thunell, S.; Anderson, D.; Harper, P.; Henrichson, A.; Floderus, Y.; Lindh, U.; Eur. J. Clin. Chem. Clin. Biochem. 1997, 35, 427.

57. Andersson, C.; Lithner, F.; J. Intern. Med. 1994, 236, 169.

58. Laiwah, A. A.; Mactier, R.; McColl, K. E.; Moore, M. R.; Goldberg, A.; Q. J. Med. 1983, 52, 92

59. Rosemarin, J. I.; Nigro, E. J.; Levere, R. D.; Mascarenhas, B. R.; Arthritis Rheum. 1982, 25, 1134.

60. McGillion, F. B.; Thompson, G. G.; Goldberg, A.; Biochem. Pharmacol. 1975, 24, 99 .

61. Rocha, M. E. M.; Bandy, B.; Costa, C. A.; de Barros, M. P.; Pinto, A. M. P.; Bechara, E. J. H.; Free Radical Res. 2000, 32, 343.

62. Lithner, F.; Wetterberg, L.; Acta Med. Scand. 1984, 215, 271.

63. Hardell, L.; Bengtsson, N. O.; Jonsson, U.; Eriksson, S.; Larsson, L. G.; Br. J. Cancer 1984, 50, 389.

64. Bengtsson, N. O.; Hardell, L.; Br. J. Cancer 1986, 54, 115.

65. Kauppinen, R.; Mustajoki, P.; Br. J. Cancer 1988, 57, 117.

66. Gubler, J. G.; Bargetzi, M. J.; Meyer, U. A.; Am. J. Med. 1990, 89, 540.

67. Thunnissen, P. L.; Meyer, J.; de Koning, R. W.; Neth. J. Med. 1991, 38,171

68. Andant, C.; Puy, H.; Bogard, C.; Faivre, J.; Soule, J. C.; Nordmann, Y.; J. Hepatol. 2000, 32, 933.

69. Yeung Laiwah, A. C.; Moore, M. R.; Goldberg, A.; Q. J. Med. 1987, 63, 377 .

70. Lindberg, R. L. P.; Martini, R.; Baumgartner, M.; Erne, B.; Borg, J.; Zielasek, J.; Ricker, K.; Steck, A.; Toyka, K. V.; Meyer, U. A.; J. Clin. Invest. 1999, 103, 1127.

71. Jover, R.; Hoffmann, F.; Scheffler-Koch, V.; Lindberg, R. L. P.; Eur. J. Biochem. 2000, 267, 7128.

72. Gorchein, A.; Webber, R.; Clin. Sci. (Colch. ) 1987, 72, 103

73. García, S. C.; Moretti, M. B.; Garay, M. V. R.; Batlle, A.; Gen. Pharmacol. 1998, 31, 579

74. McGillion, F. B.; Thompson, G. G.; Moore, M. R.; Goldberg, A.; Biochem. Pharmacol. 1974, 23, 472

75. Mustajoki, P.; Timonen, K.; Gorchein, A.; Seppalainen, A. M.; Matikainen, E.; Tenhunen, R.; Eur. J. Clin. Invest. 1992, 22, 407.

76. Emanuelli, T.; Pagel, F. W.; Alves, L. B.; Regner, A.; Souza, D. O.; Neurochem. Int. 2001, 38, 213.

77. Demasi, M.; Penatti, C. A.; DeLucia, R.; Bechara, E. J.; Free Radical Biol. Med. 1996, 20, 291.

78. Monteiro, H. P.; Abdalla, D. S.; Augusto, O.; Bechara, E. J. H.; Arch. Biochem. Biophys. 1989, 271, 206.

79. Hermes-Lima, M.; Valle, V. G.; Vercesi, A. E.; Bechara, E. J. H.; Biochim. Biophys. Acta 1991, 1056, 57

80. Helson, L.; Braverman, S.; Mangiardi, J.; Neurochem. Res. 1993, 18, 1255.

81. Bjersing, L.; Andersson, C.; Lithner, F.; Cancer Epidemiol. Biomarkers Prev. 1996, 5, 393.

82. Monteiro, H. P.; Abdalla, D. S.; Faljoni-Alario, A.; Bechara, E. J. H.; Biochim. Biophys. Acta 1986, 881, 100.

83. Härtel, H.; Walter, G.; Haseloff, R. F.; Renger, G.; J. Photochem. Photobiol. B 1996, 32, 115 .

84. Bechara, E. J. H.; Braz. J. Med. Biol. Res. 1996, 29, 841.

85. Hermes-Lima, M.; Castilho, R. F.; Valle, V. G.; Bechara, E. J. H.; Vercesi, A. E.; Biochim. Biophys. Acta 1992, 1180, 201.

86. Vercesi, A. E.; Castilho, R. F.; Meinicke, A. R.; Valle, V. G.; Hermes-Lima, M.; Bechara, E. J. H.; Biochim. Biophys. Acta 1994, 1188, 86.

87. Hermes-Lima, M.; Free Radical Biol. Med. 1995, 19, 381.

88. Pereira, B.; Curi, R.; Kokubun, E.; Bechara, E. J. H.; J. Appl. Physiol 1992, $72,226$.

89. Biempica, L.; Kosower, N.; Ma, M. H.; Goldfischer, S.; Arch. Pathol. 1974, 98, 336

90. Oteiza, P. I.; Bechara, E. J. H.; Arch. Biochem. Biophys. 1993, 305, 282.

91. Karbownik, M.; Reiter, R. J.; Garcia, J. J.; Tan, D. X.; Qi, W.; Manchester, L. C.; Biochim. Biophys. Acta 2000, 1523, 140.

92. Karbownik, M.; Tan, D. X.; Manchester, L. C.; Reiter, R. J.; Cancer Lett. 2000, $161,1$.

93. Neal, R.; Yang, P.; Fiechtl, J.; Yildiz, D.; Gurer, H.; Ercal, N.; Toxicol. Lett. 1997, 91, 169 .

94. Meneghini, R.; Benfato, M. S.; Bertoncini, C. R.; Carvalho.H.; Gurgueira S.; Robalinho, R.; Teixeira, H. D.; Wendel, C.; Nascimento, A. L. T. O.; Ciência e Cultura 1995, 47, 320

95. Carvalho, H.; Bechara, E. J. H.; Meneghini, R.; Demasi, M.; Biochem. J. 1997, 328, 827 .

96. Klausner, R. D.; Rouault, T. A.; Harford, J. B.; Cell 1993, 72, 19.

97. Hentze, M. W.; Adv. Exp. Med. Biol. 1994, 356, 119.

98. Kühn, L. C.; Baillieres Clin. Haematol. 1994, 7, 763.

99. Drapier, J. C.; Hirling, H.; Wietzerbin, J.; Kaldy, P.; Kuhn, L. C.; EMBO J. 1993, 12, 3643 
100. Pantopoulos, K.; Hentze, M. W.; EMBO J. 1995, 14, 2917.

101. Pantopoulos, K.; Hentze, M. W.; Proc. Natl. Acad. Sci. U. S. A 1995, 92, 1267.

102. Martins, E. A.; Robalinho, R. L.; Meneghini, R.; Arch. Biochem. Biophys. 1995, 316, 128.

103. Oteiza, P. I.; Kleinman, C. G.; Demasi, M.; Bechara, E. J. H.; Arch. Biochem. Biophys. 1995, 316, 607.

104. Rocha, M. E. M.; Ferreira, A. M. D. C.; Bechara, E. J. H.; Free Radical Biol. Med. 2000, 29, 1272.

105. Minotti, G.; Arch. Biochem. Biophys. 1992, 297, 189.

106. Onuki, J.; Medeiros, M. H. G.; Bechara, E. J. H.; Di Mascio, P.; Biochim. Biophys. Acta 1994, 1225, 259.

107. Di Mascio, P.; Teixeira, P. C.; Onuki, J.; Medeiros, M. H. G.; Dörnemann, D.; Douki, T.; Cadet, J.; Arch. Biochem. Biophys. 2000, 373, 368.

108. Fraga, C. G.; Onuki, J.; Lucesoli, F.; Bechara, E. J. H.; Di Mascio, P.; Carcinogenesis 1994, 15, 2241.

109. Yusof, M.; Yildiz, D.; Ercal, N.; Toxicol. Lett. 1999, 106, 41.

110. Qi, W. B.; Reiter, R. J.; Tan, D. X.; Manchester, L. C.; Calvo, J. R.; Mol. Cell. Biochem. 2001, $218,87$.

111. Kasai, H.; Nishimura, S.; Nucleic Acids Res. 1984, 12, 2137.

112. Kasai, H.; Tanooka, H.; Nishimura, S.; Gann 1984, 75, 1037.

113. Kasai, H.; Nishimura, S.; Gann 1984, 75, 841.

114. Fung, H.; Kow, Y. W.; Van Houten, B.; Mossman, B. T.; Carcinogenesis 1997, $18,825$.

115. Kasai, H.; Crain, P. F.; Kuchino, Y.; Nishimura, S.; Ootsuyama, A.; Tanooka, H.; Carcinogenesis 1986, 7, 1849.

116. Floyd, R. A.; West, M. S.; Eneff, K. L.; Hogsett, W. E.; Tingey, D. T.; Arch Biochem. Biophys. 1988, 262, 266.

117. Schneider, J. E.; Price, S.; Maidt, L.; Gutteridge, J. M.; Floyd, R. A.; Nucleic Acids Res. 1990, 18, 631.

118. Devasagayam, T. P.; Steenken, S.; Obendorf, M. S.; Schulz, W. A.; Sies, H.; Biochemistry 1991, 30, 6283.

119. Dizdaroglu, M.; Biochemistry 1985, 24, 4476.

120. Douki, T.; Martini, R.; Ravanat, J. L.; Turesky, R. J.; Cadet, J.; Carcinogenesis 1997, 18, 2385.

121. Floyd, R. A.; Watson, J. J.; Harris, J.; West, M.; Wong, P. K.; Biochem. Biophys. Res. Commun. 1986, 137, 841 .

122. Kasai, H.; Nishimura, S.; Kurokawa, Y.; Hayashi, Y.; Carcinogenesis 1987, $8,1959$.

123. Toyokuni, S.; Sagripanti, J. L.; Toxicol. Appl. Pharmacol. 1994, 126, 91.

124. Toyokuni, S.; Sagripanti, J. L.; Free Radical Biol. Med. 1996, 20, 859.

125. Fraga, C. G.; Shigenaga, M. K.; Park, J. W.; Degan, P.; Ames, B. N.; Proc. Natl. Acad. Sci. U. S. A. 1990, 87, 4533.

126. Loft, S.; Vistisen, K.; Ewertz, M.; Tjonneland, A.; Overvad, K.; Poulsen, H. E.; Carcinogenesis 1992, 13, 2241.

127. Marnett, L. J.; Carcinogenesis 2000, 21, 361.

128. Frenkel, K.; Pharmacol. Ther. 1992, 53, 127.

129. Floyd, R. A.; Carcinogenesis 1990, 11, 1447.

130. Kuchino, Y.; Mori, F.; Kasai, H.; Inoue, H.; Iwai, S.; Miura, K.; Ohtsuka E.; Nishimura, S.; Nature 1987, 327, 77.

131. Wood, M. L.; Dizdaroglu, M.; Gajewski, E.; Essigmann, J. M. Biochemistry 1990, 29, 7024.

132. Moriya, M.; Ou, C.; Bodepudi, V.; Johnson, F.; Takeshita, M.; Grollman, A. P.; Mutat. Res. 1991, 254, 281.

133. Cheng, K. C.; Cahill, D. S.; Kasai, H.; Nishimura, S.; Loeb, L. A.; J. Biol. Chem. 1992, 267, 166.

134. Moriya, M.; Proc. Natl. Acad. Sci. U. S. A. 1993, 90, 1122.

135. Le Page, F.; Margot, A.; Grollman, A. P.; Sarasin, A.; Gentil, A.; Carcinogenesis 1995, 16, 2779.

136. Shibutani, S.; Bodepudi, V.; Johnson, F.; Grollman, A. P.; Biochemistry 1993, 32, 4615 .

137. Douki, T.; Onuki, J.; Medeiros, M. H. G.; Bechara, E. J. H.; Cadet, J.; Di Mascio, P.; FEBS Lett. 1998, 428, 93.

138. Kow, Y. W.; Wallace, S. S.; Proc. Natl. Acad. Sci. U. S. A. 1985, 82, 8354

139. Wallace, S. S.; Environ. Mol. Mutagen. 1988, 12, 431.

140. Kow, Y. W.; Wallace, S. S.; Van Houten, B.; Mutat. Res. 1990, 235, 147.

141. Boiteux, S.; J. Photochem. Photobiol. B 1993, 19, 87.

142. Demple, B.; Harrison, L.; Annu. Rev. Biochem. 1994, 63, 915.

143. Hatahet, Z.; Kow, Y. W.; Purmal, A. A.; Cunningham, R. P.; Wallace, S. S.; J. Biol. Chem. 1994, 269, 18814.

144. Feig, D. I.; Reid, T. M.; Loeb, L. A.; Cancer Res. 1994, 54, 1890s.

145. Wiseman, H.; Kaur, H.; Halliwell, B.; Cancer Lett. 1995, 93, 113.

146. Beckman, K. B.; Ames, B. N.; J. Biol. Chem. 1997, 272, 19633.

147. Fearon, E. R.; Science 1997, 278, 1043.

148. Fishel, R.; Lescoe, M. K.; Rao, M. R.; Copeland, N. G.; Jenkins, N. A.; Garber, J.; Kane, M.; Kolodner, R.; Cell 1993, 75, 1027.

149. Jiricny, J.; Trends Genet. 1994, 10, 164
150. Boiteux, S.; Radicella, J. P.; Biochimie 1999, 81, 59.

151. Boiteux, S.; Radicella, J. P.; Arch. Biochem. Biophys. 2000, 377, 1

152. Basu, A. K.; O’Hara, S. M.; Valladier, P.; Stone, K.; Mols, O.; Marnett, L. J.; Chem. Res. Toxicol. 1988, 1, 53.

153. Chaudhary, A. K.; Nokubo, M.; Reddy, G. R.; Yeola, S. N.; Morrow, J. D.; Blair, I. A.; Marnett, L. J.; Science 1994, 265, 1580.

154. Vaca, C. E.; Vodicka, P.; Hemminki, K.; Carcinogenesis 1992, 13, 593.

155. Vaca, C. E.; Fang, J. L.; Schweda, E. K.; Chem. Biol. Interact. 1995, 98, 51.

156. Fang, J. L.; Vaca, C. E.; Carcinogenesis 1997, 18, 627.

157. Shapiro, R.; Hachmann, J.; Biochemistry 1966, 5, 2799.

158. Shapiro, R.; Cohen, B. I.; Shiuey, S. J.; Maurer, H.; Biochemistry 1969, 8, 238.

159. Chung, F. L.; Young, R.; Hecht, S. S.; Cancer Res. 1984, 44, 990

160. Winter, C. K.; Segall, H. J.; Haddon, W. F.; Cancer Res. 1986, 46, 5682.

161. Eder, E.; Scheckenbach, S.; Deininger, C.; Hoffman, C.; Toxicol. Lett. 1993, $67,87$.

162. Nath, R. G.; Chung, F.-L.; Proc. Natl. Acad. Sci. U. S. A. 1994, 91, 7491.

163. Douki, T.; Ames, B. N.; Chem. Res. Toxicol. 1994, 7, 511.

164. Douki, T.; Onuki, J.; Medeiros, M. H. G.; Bechara, E. J. H.; Cadet, J.; Di Mascio, P.; Chem. Res. Toxicol. 1998, 11, 150.

165. Carvalho, V. M.; Di Mascio, P.; de Arruda Campos, I.; Douki, T.; Cadet, J.; Medeiros, M. H. G.; Chem. Res. Toxicol. 1998, 11, 1042.

166. Carvalho, V. M.; Asahara, F.; Di Mascio, P.; de Arruda Campos, I.; Cadet, J.; Medeiros, M. H. G.; Chem. Res. Toxicol. 2000, 13, 397.

167. Loureiro, A. P. M.; Di Mascio, P.; Gomes, O. F.; Medeiros, M. H. G.; Chem. Res. Toxicol. 2000, 13, 601.

168. Cadet, J.; Carvalho, V. M.; Onuki, J.; Douki, T.; Medeiros, M. H. G.; Di Mascio, P. Em Exocyclic DNA adducts in mutagenesis and carcinogenesis; Singer, B.; Bartsch, H., eds.; IARC Sci. Publ.: Lyon, 1999, p. 103.

169. Marnett, L. J.; Hurd, H. K.; Hollstein, M. C.; Levin, D. E.; Esterbauer, H.; Ames, B. N.; Mutat. Res. 1985, 148, 25.

170. Dellarco, V. L.; Mutat. Res. 1988, 195, 1

171. Bjeldanes, L. F.; Chew, H.; Mutat. Res. 1979, 67, 367.

172. Bird, R. P.; Draper, H. H.; Basrur, P. K.; Mutat. Res. 1982, 101, 237.

173. Eder, E.; Schuler \& Budiawan, D. Em Exocyclic DNA Adducts in Mutagenesis and Carcinogenesis; Singer, B.; Bartsch, H., eds.; IARC Sci. Publ.: Lyon, 1999, p. 219.

174. Matijasevic, Z.; Sekiguchi, M.; Ludlum, D. B.; Proc. Natl. Acad. Sci. U. S. A. 1992, 89, 9331 .

175. Dosanjh, M. K.; Chenna, A.; Kim, E.; Fraenkel-Conrat, H.; Samson, L.; Singer, B.; Proc. Natl. Acad. Sci. U. S. A. 1994, 91, 1024.

176. Saparbaev, M.; Laval, J.; Proc. Natl. Acad. Sci. U. S. A. 1998, 95, 8508

177. Hang, B.; Chenna, A.; Rao, S.; Singer, B.; Carcinogenesis 1996, 17, 155.

178. Hang, B.; Singer, B.; Margison, G. P.; Elder, R. H.; Proc. Natl. Acad. Sci. U. S. A. 1997, 94, 12869.

179. Oesch, F.; Adler, S.; Rettelbach, R.; Doerjer, G. Em The Role of Cyclic Nucleic Acid Adducts in Carcinogenesis and Mutagenesis; Singer, B.; Bartsch, H., eds.; IARC Sci. Publ.: Lyon, 1986, p. 373.

180. Oesch, F.; Weiss, C. M.; Klein, S.; Arch. Toxicol. 1994, 68, 358.

181. Swenberg, J. A.; Fedtke, N.; Ciroussel, F.; Barbin, A.; Bartsch, H.; Carcinogenesis 1992, 13, 727.

182. Guichard, Y.; el Ghissassi, F.; Nair, J.; Bartsch, H.; Barbin, A.; Carcinogenesis 1996, 17, 1553.

183. Moller, P.; Wallin, H.; Mutat. Res. 1998, 410, 271.

184. Burcham, P. C.; Mutat. Res. 1999, 443, 11.

185. Singer, B.; Bartsch, H.; Exocyclic DNA adducts in mutagenesis and carcinogenesis; IARC Sc. Publ.: Lyon, France, 1999.

186. Bartsch, H.; Mutat. Res. 1996, 340, 67.

187. Povey, A. C.; Toxicol. Pathol. 2000, 28, 405.

188. Hemminki, K.; Koshinen, M.; Rajaniemi, H.; Zhao, C.; Regul. Toxicol. Pharmacol. 2000, 32, 264.

189. Kikuchi, G.; Kumar, A.; Talmage, P.; Shemin, D.; J. Biol. Chem. 1958, 233, 1214.

190. Butler, A. R.; George, S.; Tetrahedron 1992, 48, 7879.

191. Yamaguchi, T.; Kashige, N.; Mishiro, N.; Miake, F.; Watanabe, K.; Biol. Pharm. Bull. 1996, 19, 1261.

192. Yamaguchi, T.; Matsumoto, S.; Watanabe, K.; Tetrahedron Lett. 1998, 39, 8311.

193. Yamaguchi, T.; Eto, M.; Harano, K.; Kashige, N.; Watanabe, K.; Ito, S.; Tetrahedron 1999, 55, 675.

194. Prütz, W. A.; Biochem. J. 1994, 302, 373.

195. Hiraku, Y.; Kawanishi, S.; Cancer Res. 1996, 56, 1786.

196. Teixeira, P. C.; Onuki, J.; Medeiros, M. H. G.; Dörnemann, D.; Di Mascio, P.; Biol. Chem. 2001, 382, 913.

197. Bandy, B.; Davison, A. J.; Free Radical Biol. Med. 1990, 8, 523.

198. Yakes, F. M.; Van Houten, B.; Proc. Natl. Acad. Sci. U. S. A. 1997, 94, 514. 
199. Ames, B. N.; Shigenaga, M. K.; Hagen, T. M.; Biochim. Biophys. Acta 1995, 1271, 165

200. Salazar, J. J.; Van Houten, B.; Mutat. Res. 1997, 385, 139.

201. Hruszkewycz, A. M.; Biochem. Biophys. Res. Commun. 1988, 153, 191.

202. Allen, J. A.; Coombs, M. M.; Nature 1980, 287, 244.

203. Myers, K. A.; Saffhill, R.; O’Connor, P. J.; Carcinogenesis 1988, 9, 285.

204. Niranjan, B. G.; Bhat, N. K.; Avadhani, N. G.; Science 1982, 215, 73.

205. Richter, C.; Park, J. W.; Ames, B. N.; Proc. Natl. Acad. Sci. U. S. A. 1988, $85,6465$.

206. Chance, B.; Sies, H.; Boveris, A.; Physiol Rev. 1979, 59, 527.

207. Clayton, D. A.; Annu. Rev. Biochem. 1984, 53, 573

208. Clayton, D. A.; Doda, J. N.; Friedberg, E. C.; Proc. Natl. Acad. Sci. U. S. A. 1974, 71, 2777

209. LeDoux, S. P.; Driggers, W. J.; Hollensworth, B. S.; Wilson, G. L.; Mutat. Res. 1999, 434, 149.

210. Anderson, C. T.; Friedberg, E. C.; Nucleic Acids Res. 1980, 8, 875.

211. Gupta, P. K.; Sirover, M. A.; Cancer Res. 1981, 41, 3133.

212. Domena, J. D.; Mosbaugh, D. W.; Biochemistry 1985, 24, 7320.

213. Levin, C. J.; Zimmerman, S. B.; Biochem. Biophys. Res. Commun. 1976, $69,514$.

214. Hegler, J.; Bittner, D.; Boiteux, S.; Epe, B.; Carcinogenesis 1993, 14, 2309.

215. Croteau, D. I.; Rhys, C. M. J.; Hudson, E. K.; Dianov, G. L.; Hansford, R. G.; Bohr, V. A.; J. Biol. Chem. 1997, 272, 27338

216. Takao, M.; Aburatani, H.; Kobayashi, K.; Yasui, A.; Nucleic Acids Res. 1998, 26, 2917.

217. LeDoux, S. P.; Wilson, G. L.; Beecham, E. J.; Stevnsner, T.; Wassermann, K.; Bohr, V. A.; Carcinogenesis 1992, 13, 1967.

218. Thyagarajan, B.; Padua, R. A.; Campbell; C.; J. Biol. Chem. 1996, 271, 27536.

219. Miquel, J.; Mutat. Res. 1992, 275, 209

220. Shay, J. W.; Werbin, H.; Mutat. Res. 1987, 186, 149.

221. Pedersen, P. L.; Prog. Exp. Tumor. Res. 1978, 22, 190.

222. Hadler, H. I.; Daniel, B. G.; Cancer Res. 1973, 33, 117

223. Burdon, R. H.; Rice-Evans, C.; Free Radical Res. Commun. 1989, 6, 345.

224. Cadet, J.; Berger, M.; Douki, T.; Ravanat, J. L.; Rev. Physiol Biochem. Pharmacol. 1997, 131, 1.

225. Loft, S.; Poulsen, H. E.; J. Mol. Med. 1996, 74, 297.

226. Sancar, A.; Annu. Rev. Biochem. 1996, 65, 43.
227. Fiedler, D. M.; Eckl, P. M.; Krammer, B.; J. Photochem. Photobiol. B 1996, $33,39$.

228. Kennedy, J. C.; Pottier, R. H.; J. Photochem. Photobiol. B 1992, 14, 275.

229. Ortel, B.; Tanew, A.; Honigsmann, H.; J. Photochem. Photobiol. B 1993, $17,273$.

230. Peng, Q.; Berg, K.; Moan, J.; Kongshaug, M.; Nesland, J. M.; Photochem. Photobiol. 1997, 65, 235.

231. Fuchs, J.; Weber, S.; Kaufmann, R.; Free Radical Biol. Med. 2000, 28, 537.

232. Ames, B. N.; McCann, J.; Yamasaki, E.; Mutat. Res. 1975, 31, 347.

233. Green, M. H. L.; Arch. Toxicol. 1978, 39, 241.

234. McCann, J.; Spingarn, N. E.; Kobori, J.; Ames, B. N.; Proc. Natl. Acad. Sci. U. S. A. 1975, 72, 979.

235. Levin, D. E.; Hollstein, M.; Christman, M. F.; Schwiers, E. A.; Ames, B. N.; Proc. Natl. Acad. Sci. U. S. A. 1982, 79, 7445.

236. Levin, D. E.; Marnett, L. J.; Ames, B. N.; Proc. Natl. Acad. Sci. U. S. A 1984, 81, 4457 .

237. Little, J. W.; Mount, D. W.; Cell 1982, 29, 11.

238. Kirtikar, D. M.; Goldthwait, D. A.; Proc. Natl. Acad. Sci. U. S. A. 1974, $71,2022$.

239. Rupp, W. D.; Howard-Flanders, P.; J. Mol. Biol. 1968, 31, 291.

240. Witkin, E. M.; Bacteriol. Rev. 1976, 40, 869.

241. Eder, E.; Deininger, C.; Neudecker, T.; Deininger, D.; Environ. Mol. Mutagen. 1992, 19, 338.

242. Onuki, J.; Rech, C. M.; Umbuzeiro, G. A.; Medeiros, M. H. G.; Di Mascio, P.; Genet. Mol. Biol. 1999, 22 (4) supl., 36.

243. Onuki, J.; Rech, C. M.; Medeiros, M. H. G.; Umbuzeiro, G. A.; Di Mascio, P.; Environ. Mol. Mutagen. 2002, no prelo.

244. Nassi-Calo, L.; Mello-Filho, C.; Meneghini, R.; Carcinogenesis 1989, 10, 1055.

245. Cerutti, P.; Amstad, P.; Larsson, R.; Shah, G.; Krupitza, G.; Prog. Clin. Biol. Res. 1990, 347, 183.

246. Stadtman, E. R.; Science 1992, 257, 1220.

247. Ames, B. N.; Shigenaga, M. K.; Hagen, T. M.; Proc. Natl. Acad. Sci. U. S. A. 1993, 90, 7915.

248. Onuki, J.; Tese de Doutorado; Universidade de São Paulo, Brasil, 2000.

249. Salata, H.; Cortes, J. M.; Enriquez, D. S.; Oliva, H.; Castro, A.; Kusak, E.; Carreno, V.; Hernandez, G. C.; J. Hepatol. 1985, 1, 477.

250. Onuki, J.; Teixeira, P. C.; Medeiros, M. H. G.; Dörnemann, D.; Douki, T.; Cadet, J.; Di Mascio, P.; Cell. Mol. Biol. 2002, 48, 17. 